Title

\title{
Astrocytic VMAT2 in the developing prefrontal cortex is required for normal grooming behavior in mice
}

\section{$\underline{\text { Authors }}$}

Francesco Petrelli ${ }^{1,11}$, Tamara Zehnder ${ }^{1,11}$, Luca Pucci ${ }^{1}$, Corrado Cali'1, Bianca Maria Bondiolotti ${ }^{1}$, Alicia Molinero Perez ${ }^{1}$, Glenn Dallerac ${ }^{2}$, Nicole Déglon ${ }^{3,4}$, Bruno Giros ${ }^{5}$, Fulvio Magara ${ }^{6}$, Lorenzo Magrassi $^{7}$ Jean-Pierre Mothet ${ }^{2,8}$, Linda Simmler ${ }^{9,11}$, and Paola Bezzi ${ }^{1,10,12}$

\section{$\underline{\text { Affiliations }}$}

1: Department of Fundamental Neurosciences (DNF), University of Lausanne (UNIL), CH-1005 Lausanne, Switzerland.

2: Centre de Recherche en Neurobiologie et Neurophysiologie de Marseille, Aix-Marseille Université UMR7286 CNRS 13344 Marseille Cedex 15, France.

3: Department of Clinical Neurosciences, Laboratory of Neurotherapies and Neuromodulation (LNTM), Lausanne University Hospital (CHUV) and University of Lausanne, CH-1011 Lausanne, Switzerland;

4: Neurosciences Research Center (CRN), Laboratory of Neurotherapies and Neuromodulation (LNTM), Lausanne University Hospital and University of Lausanne, CH-1011 Lausanne, Switzerland

5: Department of Psychiatry, Douglas Hospital Research Center, McGill University, Montreal, Quebec, H4H1R3, Canada.

6: Centre for Psychiatric Neuroscience, Department of Psychiatry, Lausanne University Hospital Center, University of Lausanne, CH-1015, Lausanne, Switzerland.

7: Neurosurgery, Dipartimento di Scienze Clinico-Chirurgiche e Pediatriche, Università degli Studi di Pavia, Fondazione IRCCS Policlinico S. Matteo, 27100 Pavia, Italy.

8: "Biophotonics and Synapse Physiopathology" Team, UMR9188 CNRS - ENS Paris Saclay, 91405, Orsay, France. jean-pierre.mothet@u-psud.fr.

9: Department of Basic Neurosciences, University of Geneva, Rue Michel-Servet 1, 1206 Geneva, Switzerland

10: Department of Physiology and Pharmacology, Sapienza University of Rome, 00185 Rome, Italy

11: These authors contributed equally

12: Correspondence to Linda Simmler and/or Paola Bezzi.

\section{Contact information}

Paola Bezzi

Department of Fundamental Neurosciences 
University of Lausanne

Rue du Bugnon 9

1005 Lausanne - Switzerland

Tel 0041216925284

Email : paola.bezzi@unil.ch

Linda Simmler

Department of Basic Neurosciences

University of Geneva

Rue Michel-Servet 1

1211 Geneva - Switzerland

Phone: 0041223795390

Email: linda.simmler@unige.ch

\section{$\underline{\text { Abstract }}$}

Astrocytes control synaptic activity by modulating peri-synaptic concentrations of ion and neurotransmitters including dopamine and, as such, can be critically involved in the modulation of some aspect of mammalian behavior. Here we report that genetic mouse model with a reduced medial prefrontal cortex (mPFC) dopamine levels, arising from astrocyte-specific conditional deletion of vesicular monoamine transporter 2 (VMAT2; aVMTA2cKO mice) shows excessive grooming and anxiety-like behaviour. The VMAT2cKO mice also develop a synaptic pathology, expressed through increased relative AMPA vs. NMDA receptor currents in synapses of the dorsal striatum receiving inputs from the mPFC. Importantly, behavioural and synaptic phenotypes are prevented by reexpression of mPFC VMAT2, showing that the deficits are driven by $\mathrm{mPFC}$ astrocytes. By analysing human tissue samples, we found that VMAT2 is expressed in human mPFC astrocytes, corroborating the potential translational relevance of our observations in mice. Our study shows that impairments of the astrocytic-control of dopamine in the $\mathrm{mPFC}$ has a profound impact on circuit function and behaviours, which resemble symptoms of anxiety disorders and obsessive compulsive disorder (OCD).

$\underline{\text { Introduction }}$ 
bioRxiv preprint doi: https://doi.org/10.1101/2021.01.27.428434; this version posted January 27,2021 . The copyright holder for this preprint (which was not certified by peer review) is the author/funder. All rights reserved. No reuse allowed without permission.

Self-grooming is an innate behaviour that most animal species (including humans) practise in order to maintain bodily hygiene (1), but it can become pathological under conditions of stress or in the case of neuropsychiatric disorders (2-4), such as obsessive-compulsive disorder (OCD) and other OC-spectrum disorders, characterised by excessive repetitive behaviours (5). OCD is a highly heritable (h $2=0.27-$ $0.65)(6)$, heterogeneous and debilitating neuropsychiatric disorder that affects $2-3 \%$ of the population worldwide (7-10) and is associated with persistent intrusive thoughts (obsession), repetitive rituals (compulsion), and excessive anxiety that significantly impairs social activities. The heterogeneity of OCD is related to the various types of obsessions, compulsions and co-morbid conditions associated with it (11). In addition, there are other neuropsychiatric OC-spectrum disorders such as Tourette's syndrome and trichotillomania that share features of $\mathrm{OCD}$, particularly the occurrence of repetitive maladaptive behaviours.

The neurobiological basis of repetitive behaviours in OCD is still unclear, especially in terms of the neural circuits and neuromodulators involved. Convergent neuroimaging and neurocognitive findings support a model in which abnormal cortico-striato-thalamo-cortical (CSTC) loops play a critical role in the symptoms $(12,13)$. These findings have been confirmed by studies of genetically engineered mouse lines (14-16), which have characterised the CSTC loop dysfunctions implicated in OCD pathophysiology in detail and provided invaluable insights into the relationships between striatal (ST) dysfunctions and abnormal OCD-relevant behaviours $(14,17)$. It is still unknown whether and how upstream cortical structures are involved in generating the striatal abnormalities leading to pathological behaviours. However, it seems that prefrontal cortex (PFC) dysfunctions are central in the CSTC model as patients show orbitofrontal cortex (OFC) hyperactivity at baseline and after symptom provocation (18-20), and the PFC (and striatal) hyperactivity correlates with the severity of the obsessions, compulsions and symptom-associated affective states (21). Moreover, the persistence of maladaptive patterns of inflexible thoughts and behaviours in patients $(22,23)$ and in mouse models of OCD (24-26) indicate a lack of cognitive flexibility (i.e. the ability of the PFC to adapt behaviours in response to changing situational requirements). Preclinical studies of mouse PFC have confirmed its possible role in the pathophysiology of OCD (25,27-31), and one study of how orbitofrontal-striatal projections contribute to OCD-relevant repetitive behaviour has shown that chronic optogenetic stimulation in 
normal mice is sufficient to induce excessive grooming (31). However, despite these advances, there are fewer published studies of the PFC in the context of OCD than those of striatal abnormalities.

Over the last 20 years, studies of the neuromodulators involved in OCD have mainly concentrated on serotonergic dysfunctions because it has been shown that serotonin reuptake inhibitors (SRIs) are effective in treating the repetitive and compulsive behaviour (32-38). However, nearly half of OCD patients do not sufficiently respond to SRIs treatment (39), and it seems that the dopaminergic (DAergic) pathways are also involved in the pathogenesis of OCD (40-44), as antipsychotics as add-on medication have proved to be clinically beneficial in OCD patients who do not respond to SRIs (45-47), and microdialysis studies of rodents have shown that antipsychotics increase DA levels in the PFC $(48,49)$. The involvement of DAergic neuromodulation in the pathophysiology of the repetitive compulsive behaviours characterising OCD spectrum disorders is particularly intriguing as functional neuroimaging studies have revealed that OCD patients show abnormal hyperactivity in the PFC, where DAergic innervation is particularly abundant. However, despite the importance of the PFC and DA in inducing or aggravating the repetitive and compulsive behaviour characterising OCD, we still largely ignore the possible role of PFC DAergic dysfunctions in the pathophysiology of OCD.

In this context, it is particularly interesting to note that PFC astrocytes are endowed with the unique features of DAergic glial cells, and are responsible for regulating DA homeostasis (50). The astrocytic regulation of DA occurs in the developing PFC, and depends on the expression of vesicular monoamine transporter 2 (VMAT2), an intracellular transporter known to be involved in regulating DA homeostasis in various monoaminergic cell types (51). Astrocyte VMAT2 controls monoamine oxidase B (MAOB)dependent metabolic capacity by sequestering DA from the cytoplasm, and mice in which astrocyte VMAT2 has been conditionally deleted show increased MAOB activity and a consequently significant decrease in extracellular DA levels. The unbalanced DA levels in the PFC of mice lacking astrocyte VMAT2 has been associated with increased basal activity in PFC circuits and deficits in behavioural flexibility (50), a phenotype that is reminiscent of some of the physiological and cognitive aspects of OCD patients and mouse models of OCD (22).

The findings of this study show that VMAT2 is extensively expressed in astrocytes located in the frontal cortical tissue of mice and humans, and that mice carrying the medial PFC (mPFC) astrocyte VMAT2 
deletion have a behavioural phenotype that is similar to that of mouse models of OCD: excessive grooming and increased anxiety. These behaviours are rescued by the selective re-expression of VMAT2 in PFC astrocytes and by long-term L-DOPA treatment, thus indicating that astrocyte VMAT2 and appropriate DA levels prevent the onset of the OCD-like behaviour of aVMAT2cKO mice. Furthermore, the role of astrocyte VMAT2 in neuronal pathology is further highlighted by optogenetic projection targeting, showing that the absence of VMAT2 in mPFC astrocytes can modulate mPFC corticostriatal synaptic strength, part of the circuitry implicated in OCD.

\section{$\underline{\text { Results }}$}

\section{Loss of VMAT2 in astrocytes leads to a behavioural phenotype related to obsessive compulsive disorder}

In order to study the physiological significance of astrocytic VMAT2 in OCD- relevant phenotypes, we used our previously reported inducible knock-out mouse line (50) in which the protein can be specifically deleted in a temporally controlled manner. The mouse line is a crossing of mice harbouring the tamoxifen(TAM)-inducible cre recombinase transgene driven by the human astrocytic glial fibrillary acidic protein (hGFAPcre) promoter (52) with mice containing cre-excisable loxP sequences in the endogenous VMAT2 gene (VMAT2 $2^{\text {loxP/loxP }}$ ) (53). The progeny that inherited both alleles and were treated with TAM from P20 to P28 presented the selective deletion of astrocyte VMAT2, and are here referred to as aVMAT2cKO mice; the controls were VMAT2 ${ }^{\text {loxP/loxP }}$ mice injected with TAM (control LoxTAM). The specificity and efficacy of the TAM-induced astrocyte VMAT2 excision was confirmed in the fluorescent $\mathrm{Cre}^{\mathrm{ERT}} \mathrm{XR} 26-$ tdTomato-reporter (54) and aVMAT2cKO mice lines. Confocal microscopy revealed the expression of tdTomato in the astrocytes of different brain areas, and showed recombination in $60 \%$ of PFC astrocytes as previously reported (54); no recombination was detected in cortical neurons.

Anatomical and histological brain analyses showed that they were grossly normal (50) but, starting at 4-5 months of age, they developed facial hair loss (Figure 1a). The penetrance of this phenotype increased with age and affected most (90\%) of the transgenic mice, which developed hair loss regardless of whether they were housed alone or with cage mates. The videotaping of habituated, individually 
housed aVMAT2cKO mice, showed that they engaged in more grooming bouts and spent significantly more time self-grooming than their littermates (Figure 1b, 1c, 1d), whereas their digging and jumping activities were normal, thus indicating a possible susceptibility to the development of self-directed stereotypies (Figure 1b) (55).

As the aVMAT2cKO mice showed compulsive-like behaviour, we used open-field and elevated plus maze tests to examine anxiety-like behaviour in order to investigate whether their phenotypes further resembled OCD spectrum disorders. A novel open-field task showed that the mice engaged in less locomotor activity (Figure 1e) and spent much less time exploring the central area than their control littermates (Figure 1f), which is typical of mice with anxiety-like phenotypes. Furthermore, there was no difference between control and aVMAT2cKO mice in terms of activities along the walls and in the corners, areas that are believed to be less stressful (Figure 1g). These signs of anxiety were confirmed by the elevated plus maze test, which showed that aVMAT2cKO mice took longer to cross into the open areas (a riskier environment) and spent less time exploring the open than the closed arms of the maze (Figure 1h). Taken together, these observations indicate that aVMAT2cKO mice are characterised by excessive and compulsive self-grooming behaviour associated with increased anxiety, which can be considered analogous to the pathological repetitive behaviours associated with OCD spectrum disorders $(56,57)$.

\section{Loss of VMAT2 in astrocytes is associated with a strengthening of PFC-striatum transmission in} MSNs

The OCD-relevant repetitive behaviours and anxiety, and the significant increase in the basal activity of the mPFC observed in aVMAT2cKO mice (50), together with findings of long-lasting changes in cortical-striatal neurotransmission in animal models of compulsive behaviour (including animal models of OCD) (58), suggested that the mPFC-dorsomedial striatum (DMS) pathway (59) may be involved in the compulsiveness of aVMAT2cKO mice.

We injected an adeno-associated virus (AAV8-Syn-ChrimsonR-GFP) in the mPFC that anterogradely labelled fibre terminals in the medial part of the dorsal striatum as previously reported (59) (Figure 2a). Then, we measured the ratio between AMPA and NMDA receptor excitatory postsynaptic currents 
bioRxiv preprint doi: https://doi.org/10.1101/2021.01.27.428434; this version posted January 27, 2021. The copyright holder for this preprint (which was not certified by peer review) is the author/funder. All rights reserved. No reuse allowed without permission.

Astrocytic origin of pathological grooming

Petrelli, Zehnder et al. 2020

(EPSCs) as a proxy of excitatory synaptic strength in dorsomedial putative medium-sized spiny neurons (MSNs), using channelrhodopsin (ChR2) ChrimsonR (60) expression in the mPFC to activate cortical fibres specifically (Figure 2c). The PFC was bilaterally injected with adeno-associated virus (AAV8) to express a fusion protein of a red-shifted ChR2 and enhanced green fluorescent protein (ChrimsonRGFP) under the Syn promoter $(60,61)$ in order to target cortical pyramidal neurons of control and VMAT2cKO mutant mice (Figure 2a). Pulses of orange LED light $(593 \mathrm{~nm}, 1 \mathrm{~ms}$ pulses at $0.1 \mathrm{~Hz})$ were delivered through the patch-clamp microscope objective to the mPFC terminals in striatum slices and the EPSCs in the putative MSNs in the DMS were simultaneously recorded (Figure 2b).

Evaluation of the changes in the AMPAR: NMDAR current ratio ( $\mathrm{A} / \mathrm{N}$ ratio) in putative MSNs in the DMS showed that it was increased in the aVMAT2cKO mice (Figure $2 \mathrm{c}$ and $2 \mathrm{~d}$ ), indicative of an increase in synaptic strength. An assessment of AMPAR-mediated currents at negative $(-70 \mathrm{mV})$, reversal $(0 \mathrm{mV})$, and positive potentials $(+40 \mathrm{mV})$ in order to test for the presence of AMPARs lacking GluA2 in the same preparation gave a rectification index (RI) of 1.03 in the MSNs of the control mice and 1.09 in those of the aVMAT2cKO mice (Figure 2d), thus slightly more AMPARs lacking GluA2 were found in the absence of astrocyte VMAT2. Taken together, these findings indicate that the loss of VMAT2 in astrocytes is associated with strengthening of PFC transmission to DMS MSNs.

\section{Restoration of VMAT2 in mPFC astrocytes rescues OCD-relevant phenotypes}

To determine the significance of VMAT2 and the associated decrease in DA in the developing mPFC for the expression of OCD-relevant phenotypes, we evaluated the effects of VMAT2 re-expression in mPFC astrocytes on the increased self-grooming and anxiety-like behaviours of aVMAT2cKO mice. As shown in Figure 1, aVMATcKO mice spent significantly more time grooming in the open field than control mice. A single intracranial injection of the astrocyte-specific lentiviral vector (LentiVMAT2) $(50,62)$ at P25 (Figure 3a and 3b), which enables the selective re-expression of VMAT2 in astrocytes and normalized basal extracellular DA levels in the mPFC (50), reduced the level of aVMAT2cKO grooming activity (Figure 3c, 3d, 3e). In contrast, the control lentiviral injection (LentiGFP) did not modify the basal grooming behaviour of the control mice. In line with our previous observations, the aVMAT2cKO mice spent significantly less time in the centre of the open field than their control littermates (Figure 3h), thus indicating an anxiety-like phenotype. The injection of LentiVMAT2 corrected this phenotype but control LentiGFP did not significantly affect the centre time of the control 
mice (Figure 3h). LentiVMAT2 treatment also increased the open field locomotion activities of the aVMAT2cKO mice but not the control mice (Figure 3g). We further investigated the anxiolytic effects of VMAT2 using the elevated plus maze test. LentiVMAT2-injected aVMAT2KO mice spent more time in the open arms of the maze than the control-injected aVMAT2cKO mice (Figure 3f). Control lentiviral injection had no significant effects on any measure of anxiety in control mice, thus demonstrating that VMAT2 activity contributes to the heightened anxiety-like phenotypes of aVMAT2cKO mice.

In order to evaluate whether restoring DA levels in the mPFC during the period of mPFC maturation was effective in reducing the abnormal behaviour, the behavioural profiles of the aVMAT2cKO mice were subsequently evaluated after chronic systemic treatment with L-DOPA ( $20 \mathrm{mg} / \mathrm{kg}-1$ i.p.) or vehicle from P20 to P40. In line with the results obtained using LentiVMAT2, the increased anxiety and self-grooming significantly improved (Supplementary Figure 3).

We further examined whether the re-insertion of VMAT2 in astrocytes during postnatal mPFC development contributes to preventing the plasticity of the MSNs synapses of aVMAT2cKO mice (Figure 2) by assessing the A/N ratio at mPFC to DMS synapses. Control lentiviral injection had no significant effect, but LentiVMAT2 injection significantly prevented the increase in the A/N ratio in aVMAT2cKO mice (Figure 3i and 3j).

\section{Deletion of VMAT2 in mPFC astrocytes is sufficient to induce OCD-relevant phenotypes}

In order to assess the sufficiency of mPFC aVMAT2 deletion to induce OCD-like behavioural phenotypes, we specifically deleted astrocytic VMAT2 in the mPFC by injecting VMAT2 $2^{\text {loxPlloxP }}$ mice with a Lentiviral vector (62) carrying cre recombinase or GFP (53) on P20 (Figures 4a and 4b).

A single injection of LentiCre on P20 (Figure 4) induced phenotypes similar to those previously reported in aVMAT2cKO mice in whom VMAT2 was deleted from all astrocytes (50): decreased VMAT2 and extracellular levels of DA in the mPFC (Figure 4c), and increased spine density on P40 (Figure 4d and e). At behavioural level, LentiCre in the mPFC robustly increased the grooming activities of VMAT2 $2^{\operatorname{loxP} / \text { loxP }}$ mice, which were significantly greater than those of the VMAT2 $2^{\operatorname{loxP} / \text { loxP }}$ mice injected with LentiGFP virus (Figure $4 \mathrm{f}$ and $4 \mathrm{~g}$ ). A similar trend was observed in the anxious behaviour measured 
in the open field test and elevated plus maze (Figure $4 \mathrm{~h}$ and $4 \mathrm{i}$ ). In particular, LentiCre injection reproduced the anxiety-like phenotype of reduced open field centre time (Figure 4i) but not the decrease in distance travelled (Figure 4h). In the elevated plus maze, astrocyte-specific LentiCre injected in the mPFC had significant effects on other anxiety measures: it decreased the percentage of time spent in the open arms (Figure 4j). In brief, the results of these experiments showed that the specific deletion of VMAT2 from astrocytes in normal mice was sufficient to reproduce the core symptoms of grooming and anxiety-like behaviours that characterise the persistent OCD-like phenotype of the aVMAT2cKO mice.

\section{Expression of VMAT2 and DA metabolic pathways in human astrocytes}

In order to assess the potential translational relevance of our findings, we obtained frontal brain cortex samples from human subjects and used previously validated polyclonal antibodies raised against tyrosine hydroxylase (TH), catechol-o-methyl transferase (COMT), MAOB and VMAT2 (50) to check for the expression of bona fide proteins involved in the synthesis, storage and degradation of dopamine in astrocytes. In line with previous findings in human and rodents brain tissues $(50,63,64)$, immunolabelling experiments did not detect any signal for TH, but it did reveal the presence of COMT, MAOB and VMAT2 in $>80 \%$ of GFAP-positive cells (Supplementary Figure S5a). In particular, the VMAT2 signal was readily recognisable mainly in one of the previously identified four major morphologic sub-classes of GFAP-immunoreactive cells of adult human frontal lobe (65): large, typically tortuous and highly branched protoplasmic astrocytes with primary processes located in layers 2-6 (Figure 5a-c). Interestingly, the signal was virtually absent or weak in both human and mouse GFAP-positive cells of the visual cortex (Supplementary Figure S5b), thus further validating the specificity of the staining and confirming the frontal cortex-specific expression of VMAT2 in astrocytes. We then checked for the presence of DA in the VMAT2-expressing GFAP-positive cells using a previously validated polyclonal antibody raised against dopamine (50) (Supplementary Figure S5c). In line with findings in rodents (Figure 5c-d, mouse), immunostaining showed the co-localisation of VMAT2 and dopamine in human astrocytes located in all of the layers of human cortical brain tissue 
(Figure 5e), thus indicating that astrocytes expressing VMAT2 and dopamine are also present in human cortical tissue.

\section{$\underline{\text { Discussion }}$}

We provide evidence that VMAT2 is expressed in human astrocytes located in the frontal cortical regions and that adult mice lacking VMAT2 in PFC astrocytes show abnormal grooming behaviours and increased anxiety. This phenotype is potentially interesting because it may be related to the aetiology of human OCD spectrum disorders such as human trichotillomania, which is characterised by repetitive stereotypical hair-pulling from various sites and leads to noticeable hair loss (66).

Rodent self-grooming is now widely recognised as a suitable behavioural output for studying the neural circuits underlying the generation of complex patterns of repetitive behaviours that may be relevant to human psychiatric disorders (4) and, over the last ten years, it has been suggested that some transgenic mice characterised by aberrant repetitive grooming behaviour can be used as models of OCD or OCD spectrum disorders. The grooming behaviour of VMAT2-deficient mice has some similarities to that identified in mice lacking synapse-associated protein 90/postsynaptic density protein 5-associated protein 3 (SAPAP3-/-) (67), which essentially consists of a pathologically increased number of short grooming sessions. The complex sequenced structure of mouse self-grooming is characterised by repeated stereotyped movements or "syntactic chains" (68) that start of a series of elliptical bilateral paw strokes near the nose (paw and nose grooming) and a series of unilateral paw strokes from the mystacial vibrissae to below the eye (face grooming), followed by a series of simultaneous bilateral strokes backwards and upwards (head grooming) and body licking. The duration of a single VMAT2-deficient mouse grooming event varies widely, but more detailed analysis revealed a deficit in grooming syntax, with many shorter ( $<3$-second; data not shown) grooming events appearing by early adulthood (about P40) that seem to consist of two phases: paw and nose grooming and face grooming. The young onset of this aberrant repetitive behaviour suggests that the detection of hair loss at the front of the snout in later adulthood is due to this deficit in grooming syntax. Our observations are compatible with the early life appearance of aberrant grooming behaviour in mouse models of OCD (58) and patients with OCD and trichotillomania $(58,69)$. 
Analyses of rodent grooming behaviour have suggested that pattern-generating signals organise the physical movements made during individual grooming bouts $(3,70)$, and multiple brain regions such as the basal ganglia, striatum (ST) and various cortical areas seem to be involved in implementing the syntactic chain $(3,70)$. The execution of motor behaviour is also controlled by top-down projections from cortical areas (including the PFC) to the dorsal ST that form strong excitatory connections with striatal neurons $(71,72)$. It is believed that these cortico-striatal connections make up a neural system that is required for habit learning, the routine performance of habits, and the acquisition of stereotype behaviour, and the abnormal functioning of this circuitry has been linked to the abnormal repetitive behaviour of patients with OCD-spectrum disorders (73).

We have shown VMAT2 expression in astrocytes of the frontal and prefrontal cortex, brain areas that are associated with rodent grooming behaviour and OCD circuitry. Immunohistochemical analyses of human and rodent cortical tissue show that VMAT2 is enriched in astrocytes of the frontal cortex but undetectable in astrocytes of the visual cortex, thus suggesting that astrocyte VMAT2 plays a functional role in frontal cortical regions. VMAT2-labelled astrocytes are a sub-population of cortical astrocytes (i.e. those located in frontal cortical regions), but the fact that we found that selective inactivation of VMAT2 in the mPFC is sufficient to induce pathological OCD-related behaviour favours the hypothesis that the different astrocyte populations in the brain play distinctive roles. However, the cell mechanisms regulating VMAT2 expression in specific astrocyte sub-populations require further investigation.

The mechanism underlying the way in which astrocyte VMAT2 affects behaviour may depend on the role of the vesicular transporter in regulating extra-cellular DA levels (50). In line with this hypothesis, we found that the re-expression of VMAT2 in the PFC sub-population of astrocytes and systemic treatment with L-DOPA, which has been reported to restore DA levels in the PFC of aVMATcKO mice (50), are sufficient to rescue abnormal grooming behaviour and anxiety. This provides a causal link between the absence of VMAT2 in astrocytes, decreased DA levels and the onset of OCD-like behaviour, and supports the hypothesis that increasing DA levels in the PFC may be therapeutically beneficial to patients with OCD.

The positive effect of L-DOPA on the abnormal grooming behaviour of VMAT2-deficient mice is due to the fact that L-DOPA restores extra-cellular DA levels in the PFC, and thus restores the normal basal 
bioRxiv preprint doi: https://doi.org/10.1101/2021.01.27.428434; this version posted January 27,2021 . The copyright holder for this preprint (which was not certified by peer review) is the author/funder. All rights reserved. No reuse allowed without permission.

activity of the excitatory circuits of aVMATcKO mice (50). The presence or absence of VMAT2 in mPFC astrocytes also seems to have a detectable electrophysiological effects. Previous measurements of basal synaptic transmission made by recording input/output (I/O) curves have shown that synaptic efficacy is significantly increased in the absence of astrocyte VMAT2, and that this is due to the lack of the tonic suppression of excitatory transmission caused by DA acting on D2 receptors (50). Our use of optogenetic projection targeting allowed us to assess mPFC cortico-striatal connections by measuring the ratio between post-synaptic AMPAR and NMDAR excitatory current amplitudes, and revealed an increase in the efficacy of synaptic transmission. Like its effect on excessive grooming behaviour, the re-insertion of VMAT2 in astrocytes of the mPFC was sufficient to rescue this potentiation of synaptic transmission, thus suggesting that the abnormal repetitive behaviour is associated with stronger mPFCto-striatum transmission. Similar synaptic potentiation has been found in the orbitofrontal cortex-striatal connections of a mice model of compulsion in which the compulsive optogenetic self-stimulation of dopaminergic neurons is associated with peak activity in the terminals of projections from the orbitofrontal cortex (58), thus suggesting that compulsive behaviour in general may be explained by the failure of the top-down inhibition of stimulus-response associations attributed to the PFC $(74,75)$.

Taken together, our findings not only indicate a novel role of PFC astrocytes in regulating cortico-striatal synaptic strength through DA homeostasis, but also show a phenotype that has not been previously associated with a decrease in astrocyte VMAT2. VMAT2 is an integral membrane protein that is expressed by aminergic cells in order to transport monoamines (particularly neurotransmitters such as DA, norepinephrine, serotonin and histamine) out of the cytoplasm and into the lumen of intra-cellular vesicles, including synaptic vesicles (76). By changing cytosolic and intra-vesicular monoamine concentrations, the up- or down-regulation of VMAT2 is crucial in regulating their homeostasis. Full VMAT2 knockout is lethal, and mouse studies have established that VMAT2 plays a critical role in maintaining catecholamine and serotonin levels in the central nervous system, and ensuring the availability of monoamines for exocytotic release from neurons $(77,78)$. Given its crucial importance in regulating amines, human VMAT2 variants are very rare, but some have been associated with schizophrenia (79) and others with protection against alcohol neurotoxicity (80) Pathogenic variants in the gene encoding VMAT2 (i.e. SLC18A2) have only recently been described (81-83), cause severe 
bioRxiv preprint doi: https://doi org/10.1101/2021.01.27.428434; this version posted January 27, 2021. The copyright holder for this preprint (which was not certified by peer review) is the author/funder. All rights reserved. No reuse allowed without permission.

forms of brain DA-serotonin vesicular transport disease and a variety of symptoms such as hypotonia, parkinsonism, tremor, developmental disability, and depression. Whether SLC18A2 participates in the pathophysiology of OCD has never been investigated, but our findings indicate the existence of an OCDlike phenotype specifically caused by a knockout in this gene in astrocytes. The presence of VMAT2 in astrocytes has only recently been identified by means of transcriptome analysis and immunohistochemistry (50), and a novel mRNA splice variant of Drosophila VMAT (DVMAT-B) has been found in a small sub-set of the glial cells in the lamina of the fly's optic lobe, where it regulates the homeostasis of histamine (84). Consequently, the pathological conditions associated with the modulation of this gene in astrocytes are still unknown and require further investigation.

\section{Legends}

Figure 1

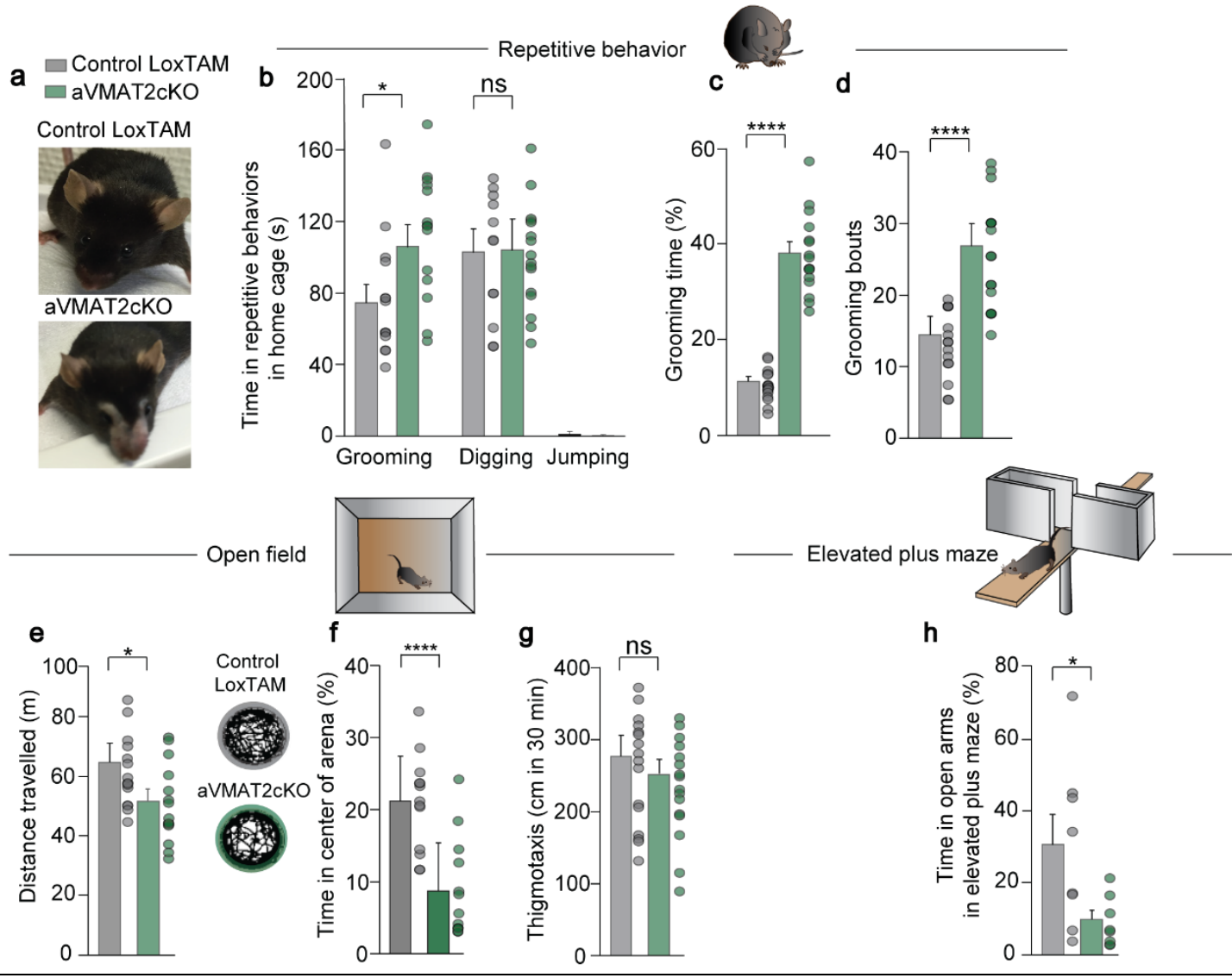




\section{Figure 1. Facial lesions, excessive grooming and anxiety-like behaviours in aVMAT2cKO mice}

a) aVMAT2cKO mice that have removed hair from facial regions without creating large lesions. b-d) Repetitive behavioural tasks. b) The histograms show the average time that control LoxTAM (grey) and aVMAT2cKO mice (green) spent in grooming, digging and jumping. The error bars indicate the SEM ${ }^{*} \mathrm{p}<0.005$ ( $\mathrm{n}=16$ mice in each group; unpaired Student's t-test). c) The graph shows the percentage of time that the control LoxTAM and aVMAT2cKO mice spent in grooming $* * * * p<0.0001(\mathrm{n}=15$ in each group; unpaired Student's t-test). The error bars indicate the SEM. d) The graph shows the grooming bouts of the control LoxTAM and aVMAT2cKO mice $* * * * \mathrm{p}<0.0001$ ( $\mathrm{n}=15$ in each group; unpaired Student's t-test). The error bars indicate the SEM. e-g) Open field tasks. The histograms show the average total distance travelled by control LoxTAM and aVMAT2cKO mice during 10 minutes of free exploration of a maze (e), and the average percentage of time that control LoxTAM and aVMAT2cKO mice spent (f) in the centre of the arena, and (g) thigmotaxis $(\mathrm{cm})$ over 30 minutes $* \mathrm{p}<0.01$; $* * * * \mathrm{p}<0.0001(\mathrm{n}=10-16$ in each group; unpaired Student's t-test). The error bars indicate the SEM. h) Elevated plus maze tasks. The histograms show the average percentage of time that the control LoxTAM and aVMAT2cKO mice spent in the open arms. The error bars indicate the SEM. ${ }^{*} \mathrm{p}<0.01$ ( $\mathrm{n}=8$ in each group unpaired Student's t-test). 
Figure 2

a

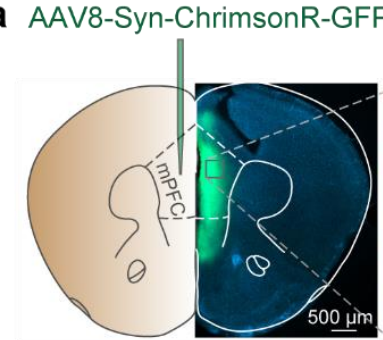

$\square$ Control LoxTAM

aVMAT2CKO

C

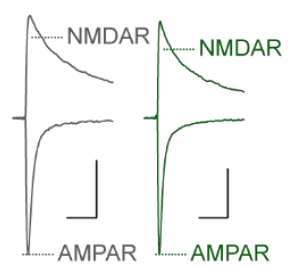

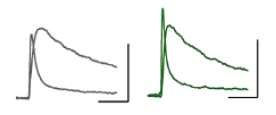

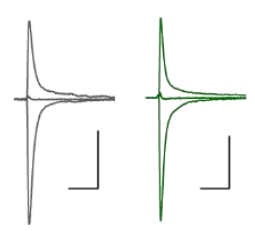

b

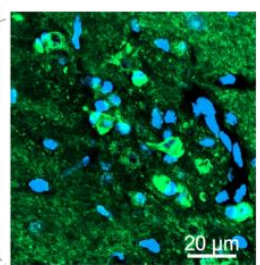

d
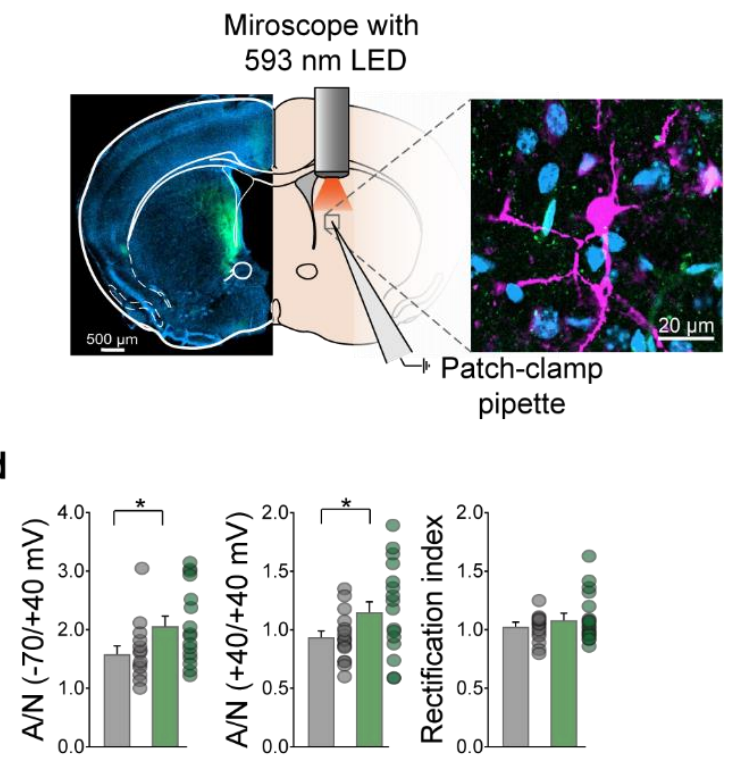

Figure 2. Alterations in mPFC-to-DMS synapses of aVMAT2cKO mice.

a) Location of virus injection and infection. AAV8-Syn-ChrimsonR-GFP was injected into the mPFC of the control LoxTAM and aVMAT2cKO mice. Cell nuclei were stained with Hoechst (blue). b) Whole-cell patch clamp recordings of striatal slices. The terminals of the mPFC-to-dorsomedial striatum (DMS) projections were stimulated with orange light $(593 \mathrm{~nm})$, and the light-evoked currents were recorded in putative medium-size spiny neurons (MSNs). For illustrative purposes, a patch-clamped MSN was filled with biocytin (pink in right-hand picture). c) Example traces of patch-clamp recordings from LoxTAM (grey) and aVMAT2cKO mice (green): left: A/N (-70/+40 mV); top right: A/N (+40/+40 $\mathrm{mV}$ ); bottom right: rectification index. d) $\mathrm{A} / \mathrm{N}$ ratios at holding currents of $-70 /+40 \mathrm{mV}$ (left panel; $\mathrm{n}$ $($ cells $)=18$ LoxTAM, 19 aVMAT2cKO; Mann-Whitney test, ${ }^{*} \mathrm{p}<0.05$ ) and $+40 /+40 \mathrm{mV}$ (middle panel; $\mathrm{n}$ (cells) = 17 LoxTAM, 20 aVMAT2cKO; unpaired t-test: *p <0.05), were significantly increased in the aVMAT2cKO mice, but the rectification index (right panel) was not significantly different between genotypes $(\mathrm{n}(\mathrm{cells})=18$ LoxTAM, 20 aVMAT2cKO; Mann-Whitney test: $\mathrm{p}=0.89$ ). Data are mean \pm SEM. 
Figure 3

Astrocyte-specific Lenti-GFPNMAT2
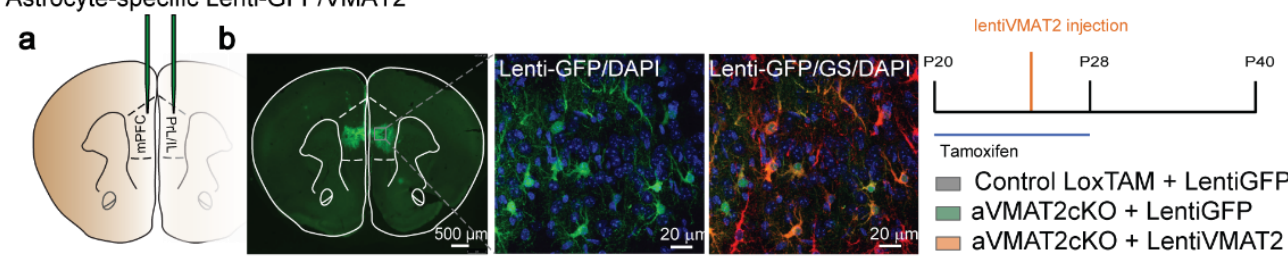

Repetitive behavior
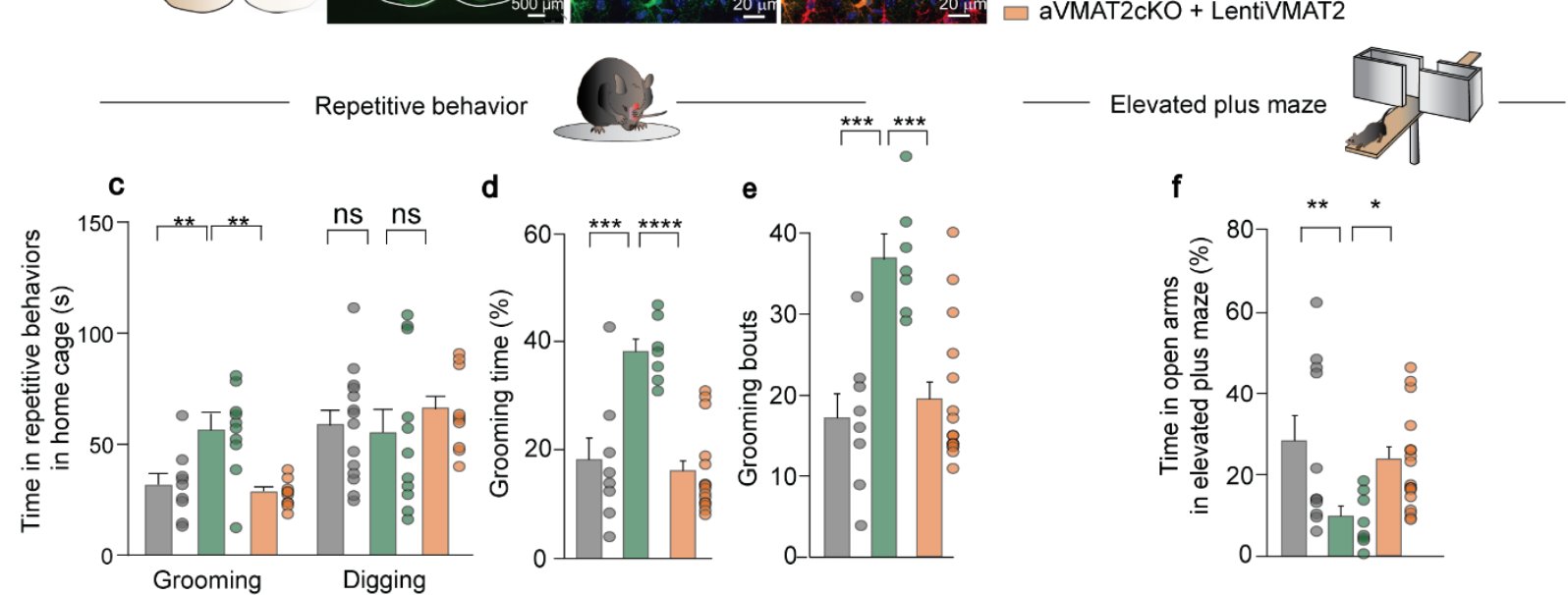

d
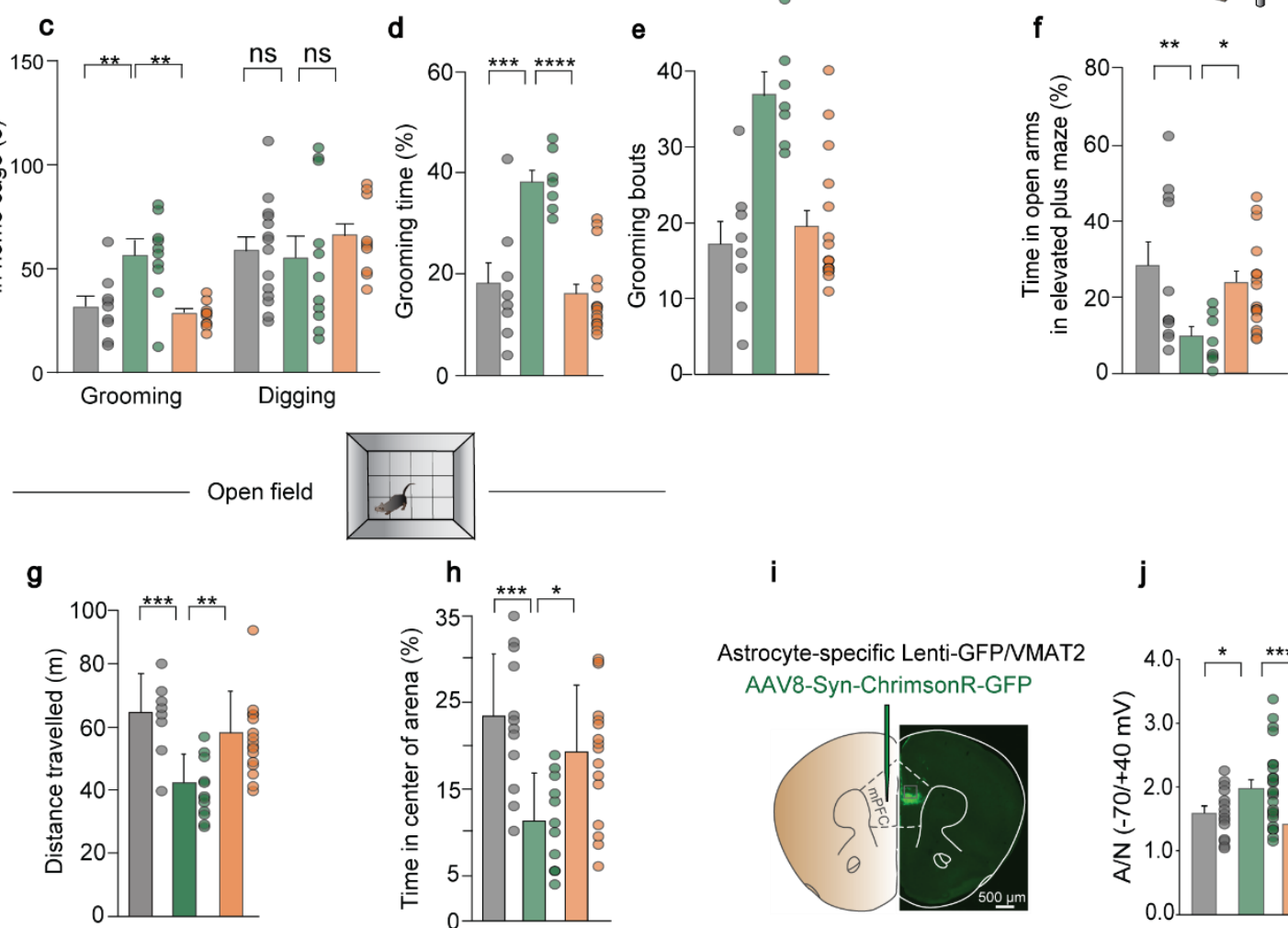

e

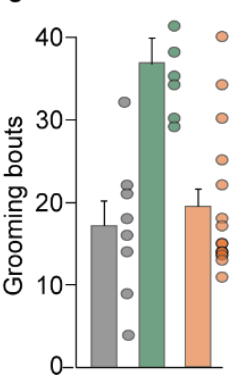

Figure 3. Astrocytic VMAT2 re-expression in the mPFC rescues the behavioural deficits and synaptic alterations of aVMAT2cKO mice. a) Schematic representation of the control GFP virus (LentiGFP) or LentiVMAT2 virus injection in the mPFC (prelimbic/infralimbic). b) Left: representative confocal coronal image showing the infection in the mPFC. Scale bar $=500 \mu \mathrm{m}$. Centre: high magnification confocal images of LentiGFP (green), DAPI (blue) and glutamine synthase (GS) (red) in the mPFC. Scale bar $=20 \mu \mathrm{m}$. Right: event timeline of intra-peritoneal injections of tamoxifen (P20P28) and local infection with LentiVMAT2 or LentiGFP (P25). Behavioural and patch-clamp experiment were conducted starting P40. c-e) Repetitive behavioural tasks. (c) Average time that control LoxTAM mic (grey), aVMAT2cKO mice infected with LentiGFP virus (green) and aVMAT2cKO mice 
infected with LentiVMAT2 virus (orange) spent in grooming and digging. ${ }^{*} \mathrm{p}<0.005$ ( $\mathrm{n}=8$ each group; one-way ANOVA, followed by Tukey's post hoc HSD test) (d) Percentage of time that the control LoxTAM and aVMAT2cKO mice infected with LentiGFP (grey and green) or lentiVMAT2 virus (orange) spent in grooming $* * * \mathrm{p}<0.001, * * * * \mathrm{p}<0.0001 \quad(\mathrm{n}=8-10$; one-way ANOVA, followed by Tukey's post hoc HSD test). (e) The graph shows the grooming bouts of control LoxTAM and aVMAT2cKO mice infected with LentiGFP (grey and green) or lentiVMAT2 virus (orange) *** $\mathrm{p}<0.001$ ( $\mathrm{n}=8$ each group; one-way ANOVA, followed by Tukey's post hoc HSD test). f) Elevated plus maze tasks. The histograms show the average percentage of time that control LoxTAM and aVMAT2cKO mice infected with LentiGFP virus (grey and green) or lentiVMAT2 virus (orange) spent in the open arms. ${ }^{*} \mathrm{p}<0.01,{ }^{* *} \mathrm{p}<0.005$ ( $\mathrm{n}=10-14$; one-way ANOVA, followed by Tukey's post hoc HSD test) $\mathbf{g}$-h) Open field tasks. (g) The histograms show the average total distance travelled by control LoxTAM and aVMAT2cKO mice infected with LentiGFP (grey and green) or lentiVMAT2 virus (orange) during 10 minutes of free exploration of a maze, and (h) the average percentage of time they spent in the center of the arena. $* \mathrm{p}<0.05, * * \mathrm{p}<0.005, * * * \mathrm{p}<0.001$ ( $\mathrm{n}=9-12$ in each group, one-way ANOVA, followed by Tukey's post hoc HSD test). i-j) Ex vivo slice electrophysiology. (i) Schematic of virus injection. (j) The aVMAT2cKO mice injected with lentiGFP (green) showed a significantly higher $\mathrm{A} / \mathrm{N}$ ratio (measured at holding currents $-70 /+40 \mathrm{mV}$ ) compared to the LoxTAM + lentiGFP control group (grey), but the selective re-expression of VMAT2 in the mPFC of aVMAT2cKO mice (orange) prevented the emergence of the synaptic phenotype (n (cells)= 15 LoxTAM + lentiGFP, 25 aVMAT2cKO + lentiGFP, 22 aVMAT2cKO + lentiVMAT2; one-way ANOVA: P = 0.0009, F(2,59) = 7.948; Tukey's post hoc test: *p <0.05, ***p <0.001)(J). The error bars indicate SEM. 
Figure 4
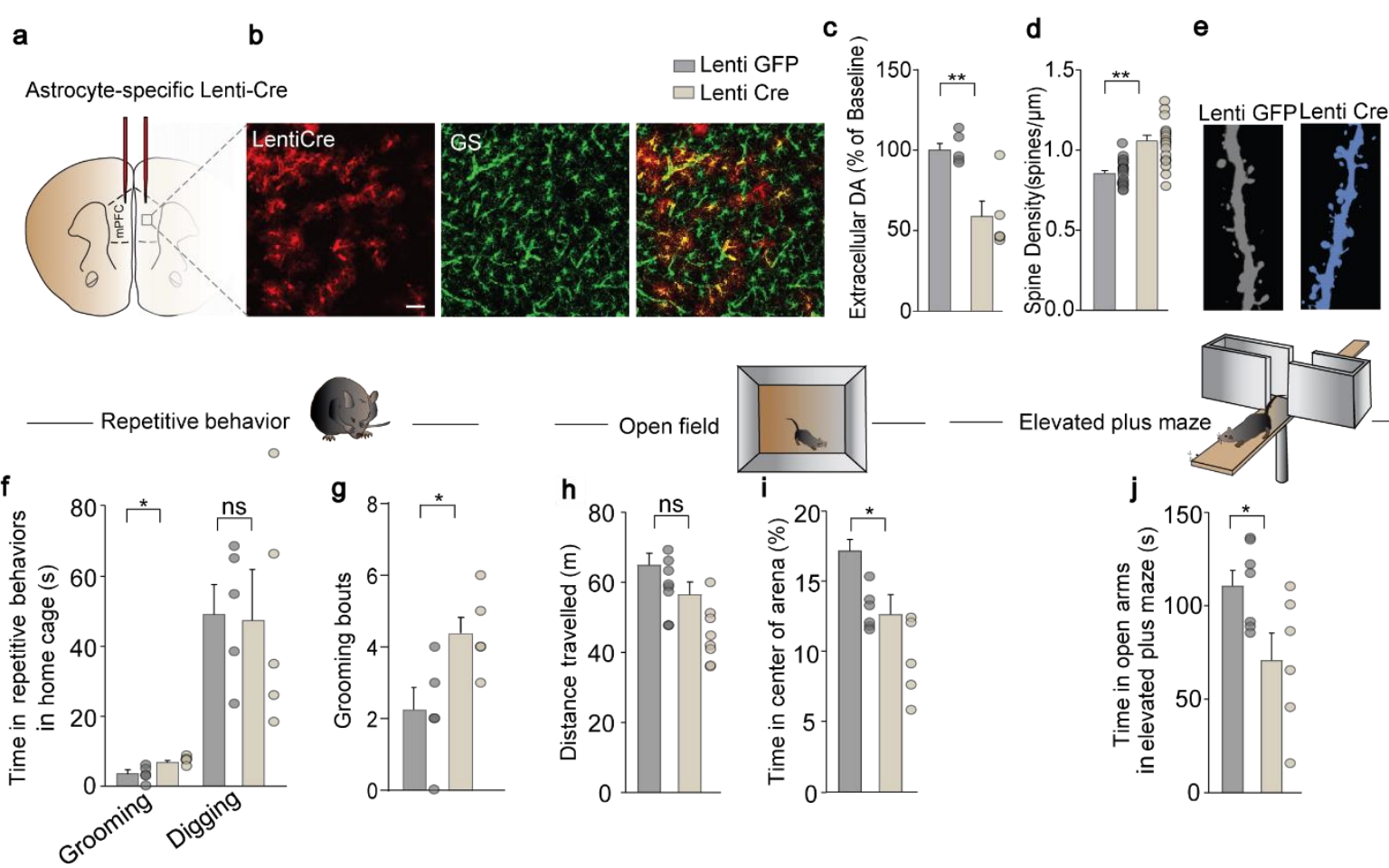
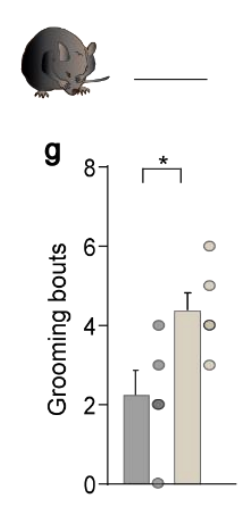

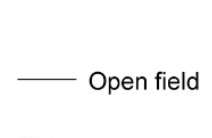

h

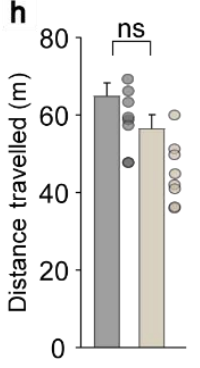

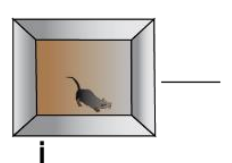

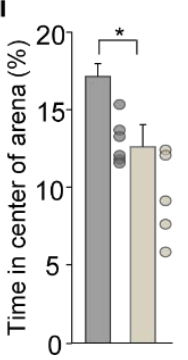

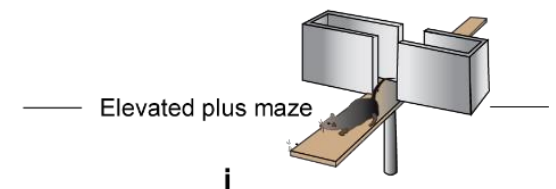

Figure 4. The deletion of VMAT2 in mPFC astrocytes is sufficient to cause OCD-relevant behavioural deficits. a) Schematic representation of Lentiviral vector carrying cre recombinase (LentiCre) or GFP (LentiGFP) injection in the mPFC (prelimbic/infralimbic). b) Representative highmagnification confocal images of LentiCre (red) and GS (green) in the mPFC. Scale bar $=50 \mu \mathrm{m} \mathrm{c}$ ) Histograms show average DA levels calculated in extra-cellular perfusates of in vivo microdialysis in the PFC of control VMAT2 $2^{\text {loxp/loxp }}$ mice infected with LentiGFP (grey) and VMAT2 $2^{\text {loxp/loxp }}$ mice infected with LentiCre virus (beige), expressed as fold percentages of baseline levels. ${ }^{* *} \mathrm{p}<0.01$ ( $\mathrm{n}=5$ each group, unpaired Student's t-test). The error bars indicate the SEM. d) Histograms of spine density calculated in layer V of the PFC of control LoxTAM-ThyEGFP mice and VMAT2 $2^{\text {loxp/loxp }}$-ThyEGFP mice infected with LentiCre virus. ${ }^{* *} \mathrm{p}<0.01$ ( $\mathrm{n}=16$ each group, unpaired Student's t-test). The error bars indicate the SEM. e) Representative confocal images showing Layer V mPFC dendritic spines in control LoxTAMThyEGFP mice and VMAT2 $2^{\text {loxp/loxp }}-$ ThyEGFP mice infected with LentiCre virus. f-g) Repetitive behavioural tasks: (f) the histograms show the average time that control VMAT2 $2^{\text {loxp/loxp }}$ mice infected with LentiGFP (grey) and VMAT2 ${ }^{\text {loxp/loxp }}$ mice infected with LentiCre virus (beige) spent in grooming and digging. ${ }^{*} \mathrm{p}<0.05$ ( $\mathrm{n}=5$ each group, unpaired Student's t-test).The error bars indicate the SEM. (g) 
bioRxiv preprint doi: https://doi.org/10.1101/2021.01.27.428434 this version posted January 27, 2021. The copyright holder for this preprint (which was not certified by peer review) is the author/funder. All rights reserved. No reuse allowed without permission.

The graph shows the grooming bouts of VMAT2 $2^{\text {loxp/loxp }}$ mice infected with LentiGFP (grey) and VMAT2 $2^{\text {loxp/loxp }}$ mice infected with LentiCre virus (beige). ${ }^{*} \mathrm{p}<0.05$ ( $\mathrm{n}=5$ each group, unpaired Student's t-test). The error bars indicate the SEM. h-i) Open field tasks. (h) The histograms show the average total distance travelled by VMAT2 $2^{\operatorname{loxp} / \text { loxp }}$ mice infected with LentiGFP and VMAT2 $2^{\text {lox/ploxp }}$ mice infected with LentiCre virus (beige) during 10 minutes of free exploration of a maze ( $\mathrm{n}=5$ each group, unpaired Student's t-test), and (i) the average percentage of time they spent in the centre of the arena. ${ }^{*} \mathrm{p}<0.05$ ( $n=5$ each group, unpaired Student's t-test).The error bars indicate the SEM. j) Elevated plus maze. The histograms show the average percentage of time that VMAT2 $2^{\text {loxp/loxp }}$ mice infected with LentiGFP (grey) and VMAT2 $2^{\text {loxp/loxp }}$ mice infected with LentiCre virus (beige) spent in the open arms. ${ }^{*} \mathrm{p}<0.05$ ( $\mathrm{n}=5$ each group, unpaired Student's t-test).The error bars indicate the SEM.

\section{Figure 5}

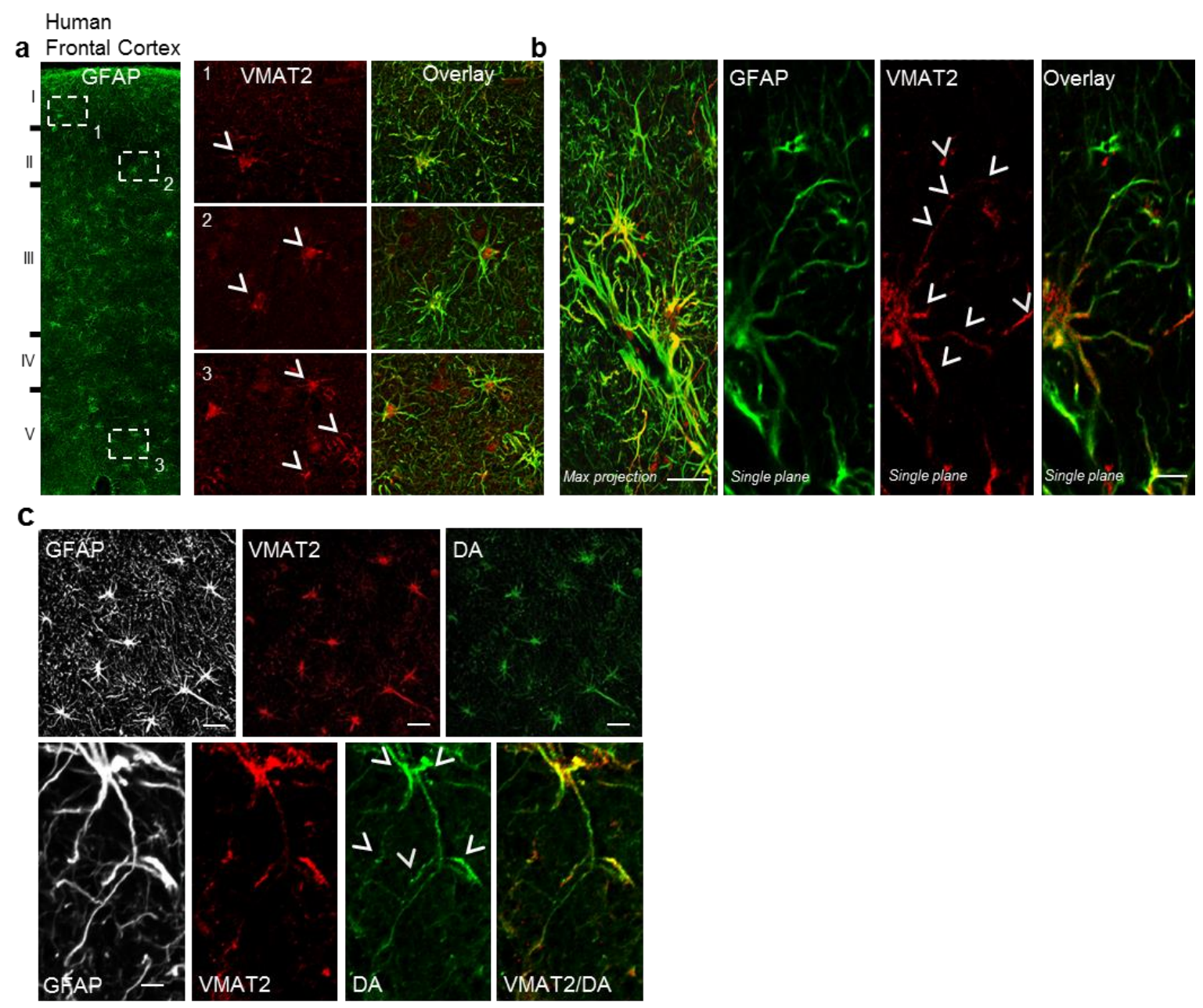


Figure 5. Expression of VMAT2 in astrocytes of the human brain frontal cortex. All images (representative of six slices from two tissue samples) are z projections of stacks 8 - $\mu$ m thick. (a-b) The expression of VMAT2 (red) in the cell bodies and processes of astrocytes identified by the cytoplasmic marker GFAP. Some astrocytes exhibit a high VMAT2 labeling of the soma (arrowheads, high magnification in a), whereas in others, VMAT2 labeling is mainly expressed on processes (arrowheads, high magnification in b). Bar, $30 \mu \mathrm{m}$ (c) The expression of VMAT2 and dopamine in the cell bodies and processes of astrocytes identified by the cytoplasmic marker GFAP. Bar, $30 \mu \mathrm{m}$

\section{METHODS}

\section{Maintenance, breeding and genotyping.}

All of the animal studies were approved by the Service de la consommation et des affaires vétérinaries $d u$ Canton Vaud, the Institutional Animal Care and Use Committee of the University of Geneva and the animal welfare committee of the Canton of Geneva, in accordance with Swiss law. The mice were grouphoused with littermates in standard housing with a 12:12-hour light:dark cycle. The hGFAPcre ${ }^{\text {ERT2 }}$ mice (85) and ROSA26- eYFP-hGFAPcre ${ }^{\text {втт2 }}$ mice (86) were obtained from Frank Kirchhoff (Molecular Physiology, University of Saarland, Germany), the VMAT2 $2^{\text {Loop/Loop }}$ mice (53) from Bruno Giros (Douglas Mental Health University Institute, Canada), and the tdtomato ${ }^{\text {lox/lox }}$ mice (AI14, Jackson Lab) and Thy1-EGFP mice from Joshua R. Sanes (Harvard University, USA). The mice used had a C57BL/6 background.

The hGFAPcre ${ }^{\mathrm{ER}_{\mathrm{T} 2}}$ sequence was identified from phalange biopsies using the following primers: 5'-

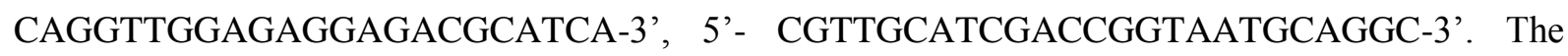
VMAT2 $2^{\text {lox/lox }}$ sequence was identified using the following primers: 5'GACTAGGGACAGCACAAATCTCC-3', 5'-GAAACATGAAGGACAACTGGGACCC-3'. The ROSA26-EYFP sequence was identified using the following primers: 5'AAAGTCGCTCTGAGTTGTTAT-3', 
The PCR reaction product coupled with Syber green migrated in a 1.5\% agarose gel, and the bands were revealed by UV light.

\section{Tamoxifen treatment}

Tamoxifen (TAM, Sigma-Aldrich) was injected on P20; the treatment protocol has been previously described (50-52)

\section{Virus preparation}

Self-inactivated (SIN) lentiviruses contain the central polypurine tract (cPPT) sequence, the mouse phosphoglycerate kinase I promoter (PGK), the woodchuck post-regulatory element (WPRE) sequence, and the target sequence of miR124 (62). A Gateway system (Invitrogen) was used to clone mouse VMAT2 and GFP cDNA, into the pENTR-D-TOPO plasmid (Invitrogen) and perform an LR clone reaction to transfer it into the destination lentiviral vector SIN-cPPT-PGK-Gateway-WPRE-miR124T plasmid. The viruses (lentiGFP, lentiVMAT2 and lentiCre) were produced in 293T cells using a fourplasmid system as previously described (87), and were pseudotyped using the G protein of mokola lyssaviruses (62).

\section{Stereotaxic intracranial injections}

P25 mice were anesthetised using isoflurane at 5\% (w/v), placed in a small animal stereotaxic frame (David Kopf Instruments), and maintained at 2.5\% isoflurane (w/c) for the duration of surgery. Corneal and pinch reflexes were regularly tested in order to confirm the depth of the anesthesia. Lacryvisc (Aicon, Switzerland) was used to prevent corneal drying, and lidocaine was topically applied to the skin overlying the skull. After exposing the skull under aseptic conditions, a small hole was drilled into the skull overlying the prefrontal cortex (AP $+2.0 \mathrm{~mm}, \mathrm{~L} \pm 0.2 \mathrm{~mm}$ and DV $-2.0 \mathrm{~mm}$ ) [Sohal et al., 2009]. LentiVMAT2, lentiCre and/or lentiGFP were injected ( $1 \mu$ l total volume) bilaterally through a Hamilton syringe at a rate of $100 \mathrm{nl}$ min-1 using a CMA400 Pump (CMA System). Adeno-associated virus AAV8hSyn-Chrimson-GFP (0.8 $\mu \mathrm{L}$ total volume; Duke University, Durham, USA) was injected at P30 into control LoxTAM and aVMAT2cKO mice bilaterally using a thin glass pipette connected to an injection 
wheel. After the surgical procedures, the mice were returned to their home cages at least for two weeks in order to allow maximum gene expression.

\section{Tissue preparation, immunohistochemistry and histology}

The mice were deeply anesthetised using intraperitoneal sodium pentobarbitone $(6 \mathrm{mg} / 100 \mathrm{~g}$ body weight) and immediately perfused intracardiacally with fresh $4 \%$ paraformaldehyde in $0.1 \mathrm{M}$ phosphatebuffered saline (PBS, pH 7.4). Their brains were post-fixed overnight, equilibrated in $30 \%$ sucrose at $20^{\circ} \mathrm{C}$ using a cryostat (Leica), and stored at $-80^{\circ} \mathrm{C}$.

Brain sections were permeabilised for 45 minutes in phosphate-buffered saline containing $0.3 \%$ Triton $\mathrm{X}-100$, and $15 \%$ donkey or goat serum, and then immunolabelled overnight at $4{ }^{\circ} \mathrm{C}$ using the following primary antibodies: mouse-GS (Chemicon, 1:1000) (88), rabbit-GFP (Chemicon, 1:200) (89), rabbitGFAP (Chemicon, 1:1000), rabbit-OCT3 (Alpha Diagnostics, 1:100) (63), mouse-dopamine (Millipore, 1/100), rabbit-dopamine (Millipore, 1/1500), mouse-COMT (BD-Transduction Lab, 1/1000) goatMAOB (Santa Cruz, 1:100), rabbit-VMAT2 (Synaptic System, 1:5600; Chemicon, 1:1000), and rabbitTH (Millipore, 1:1000) (90). The day after incubation with primary antibodies, the brain sections were washed three times in PBS for 10 minutes and then incubated for 1.5 hours at room temperature with fluorescent secondary antibodies (AlexaFluor, Invitrogen Molecular Probes, Eugene, Oregon, USA: goat anti-mouse 488, 555, and 633; goat anti-rabbit 488, 555, and 633; and donkey anti goat 488; 1:300 and 1:400) diluted in PBS. Finally, the nuclei were counterstained with 4', 6-diamidino-2-phenylindole (DAPI) (Invitrogen, 1:10000) and then washed before mounting with FluorSave (Calbiochem).

The brain was extracted and washed in PBS. Fragments of normal structure from human brain temporal cortices were removed as part of the planned margin of resection surrounding a neoplastic lesion from patients operated at the Section of Neurosurgery in the Policlinic San Matteo. Surgery was performed according to the recommendations of the Institutional Review Boards and in full agreement with the Declaration of Helsinki. Samples were fixed in $4 \%$ formaldehyde for $24 \mathrm{~h}$ and then washed in PBS. Human subjects samples from informed and consenting human patiens were collected before 2011 as previously described (91). 
All images were collected on a Leica confocal imaging system (TCS SP5) with a 40x (1.4 NA) or 63x (1.4 NA) oil immersion objective. Sections were acquired every $0.4 \mu \mathrm{m}$, and the confocal images were analysed using Imaris 7.6.3 (Bitplane AG, Zurich, Switzerland) or Adobe Photoshop CS5 software (Adobe System Inc., San José, California, USA) .

\section{In vivo microdialysis}

The mice were anaesthetised with isoflurane and placed in a stereotaxic frame using a mouse adaptor (David Kopf Instruments) with modified ear bars. Microdialysis probes were implanted in the PFC at the following coordinates relative to the bregma: $\mathrm{AP}+2.0 \mathrm{~mm}, \mathrm{ML}+0.5 \mathrm{~mm}$ and $\mathrm{DV}-3.0 \mathrm{~mm}$, with the tooth-bar set at $0 \mathrm{~mm}$. The active dialysis surface length of the membrane was $2 \mathrm{~mm}$. The probe was secured in place using dental cement on the skull.

The microdialysis experiments started 24 hours after surgery. Ringer solution $(125 \mathrm{mM} \mathrm{NaCl}, 2.5 \mathrm{mM}$ $\left.\mathrm{KCl}, 1.26 \mathrm{mM} \mathrm{CaCl}_{2}, 1.18 \mathrm{mM} \mathrm{MgCl}, 0.20 \mathrm{mM} \mathrm{NaH}_{2} \mathrm{PO}_{4}\right)$ was perfused through the microdialysis probe at a flow rate of $1.0 \mu \mathrm{l} / \mathrm{min}$ using a high precision pump (CMA 400 syringe pump, CMA Sweden) $(50,91)$. The experiments were performed during the light period of the light/dark cycle, and the mice were tested in their home cages. After an equilibration period of at least two hours, the dialysates were collected into small Eppendorf tubes containing $11.7 \mu \mathrm{L}$ of acetic acid every 30 minutes, and stored at $-69^{\circ} \mathrm{C}$ until high-performance liquid chromatography (HPLC) analysis.

Dopamine levels were quantified by means of HPLC with electrochemical detection as previously described (50) with some modifications. The samples were injected into an MD-150 column (3 M, 3.2x150 mm, Thermo Fisher Scientific,) using a Thermo Scientific Dionex Ultimate 3000, and dopamine was detected at $32^{\circ} \mathrm{C}$ using an ECD-3000RS electrochemical detector (Thermo Fisher Scientific) set at a potential of $250 \mathrm{mV}$ against an $\mathrm{Ag} / \mathrm{AgCl}$ reference electrode. The signal was analysed using Cromeleon, software. The mobile phase was $75 \mathrm{mM}$ sodium dihydrogen phosphate monohydrate, $1.7 \mathrm{mM}$ ottane sulphonic acid sodium, $100 \mathrm{M}$ triethylamine (TEA), 25 M EDTA, 10\% acetonitrile, $\mathrm{pH}$ 3.00 with phosphoric acid. The flow rate was $0.5 \mathrm{~mL} / \mathrm{min}$. 


\section{Morphological analysis of dendrites and spines}

Dendritic spine density and spine morphology was assessed as previously described $(50,91)$. The spine analysis was made using two fluorescent transgenic mice strains: control LoxTAM-Thy1EGFP and VMAT2 $2^{\text {loxp/loxp }}$-Thy1EGFP mice obtained by crossbreeding Thy1EGFP with VMAT2 ${ }^{\text {loxp/loxp }}$ mice. Confocal microscopy of post-fixed slices was performed using a Leica confocal imaging system (TCS SP5) with a $40 \times(1.8$ NA) or $63 x$ ( 2.8 NA) oil immersion objective. The mPFC field between Bregma coordinates $2.34 \mathrm{~mm}$ and $1.7 \mathrm{~mm}$ was analysed, with $50 \mu \mathrm{m}$ brain sections being acquired every $0.4 \mu \mathrm{m}$. The number of spines on 10-20 neurons per mouse was counted using image $\mathrm{J}$ software, and spine density was expressed as the number of spines divided by dendritic length (92).

\section{Patch-clamp recordings}

The mice were anesthetised with isoflurane (5\%) and decapitated, and their brains were quickly removed. Brain slices (220 $\mu \mathrm{m}$ thick) were cut using a vibratome in ice-cold oxygenated artificial cerebrospinal fluid (aCSF) containing $\mathrm{NaCl} 119$ mM, D-glucose $11 \mathrm{mM}, \mathrm{NaHCO}_{3} 26.2 \mathrm{mM}, \mathrm{KCl} 2.5$ $\mathrm{mM}, \mathrm{MgCl}_{2} 1.3 \mathrm{mM}, \mathrm{NaH}_{2} \mathrm{PO}_{4} 1 \mathrm{mM}$, and $\mathrm{CaCl}_{2} 2.5 \mathrm{mM}$. The slices were re-covered in aCSF at $30^{\circ} \mathrm{C}$ for 15 minutes, and then kept at room temperature until use. The recordings were made in aCSF with $100 \mu \mathrm{M}$ picrotoxin at $30^{\circ} \mathrm{C}$. The internal solution consisted of $130 \mathrm{mM} \mathrm{CsCl}, 4 \mathrm{mM} \mathrm{NaCl}, 5 \mathrm{mM}$ creatine phosphate, $2 \mathrm{mM} \mathrm{MgCl}$, 2 mM Na 2 ATP, $0.6 \mathrm{mM} \mathrm{Na} 3 \mathrm{GTP}, 1.1 \mathrm{mM}$ EGTA, $5 \mathrm{mM}$ HEPES, $5 \mathrm{mM}$ QX314, and 0.1 mM spermine. The currents were amplified using Multiclamp 700B (Axon Instruments), filtered at $2.2 \mathrm{~Hz}$, and digitalized at $20 \mathrm{~Hz}$. No correction was made for liquid junction potential (-3 $\mathrm{mV}$ ). Cells with more than $20 \%$ change in access resistance were discarded. The light-evoked currents were induced at $0.1 \mathrm{~Hz}(1 \mathrm{~ms}$ pulse, $593 \mathrm{~nm} \mathrm{LED})$. The $\mathrm{A} / \mathrm{N}$ ratio was calculated as the amplitude of the AMPA receptor currents recorded at $-70 \mathrm{mV}$ divided by the amplitude of the trace at $+40 \mathrm{mV} 20 \mathrm{~ms}$ after the peak. In some recordings, the NMDA receptor currents were blocked using $50 \mu \mathrm{M}$ D-2-amino5-phosphonopentanoate (AP-5). The NMDA receptor traces were computed by subtracting the traces recorded at $+40 \mathrm{mV}$ in the presence of $\mathrm{AP}-5$ from the traces recorded at $+40 \mathrm{mV}$ in the absence of $\mathrm{AP}$ 5. The rectification index was calculated as chord conductance at $-70 \mathrm{mV}$ divided by chord conductance at $+40 \mathrm{mV}$. 


\section{Behavioural protocols}

Open field test: The diameter of the round area used for the open field test was $70 \mathrm{~cm}$, and the central zone line was $25 \mathrm{~cm}$ from the edge. The mice were placed in the centre of the area at the beginning of the test, and their movements were video-recorded and subsequently analysed using ANY-maze 4.7 (Stoelting).

Elevated plus-maze: The elevated plus-maze consisted of two open arms, two closed arms, and a central area elevated to a height of $50 \mathrm{~cm}$ above the floor. Mice were placed in the central area and allowed to explore the space for eight minutes.

Repetitive behaviours: The mice were observed for 10 minutes in their home cages equipped with fresh bedding, and the time spent in repetitive behaviours (grooming, digging and jumping) was measured. Grooming was defined as stroking or scratching of the face, head or body with the two forelimbs, or licking the body; digging was defined as the co-ordinated use of both forelimbs or hind legs to dig out or displace bedding materials; jumping was defined as rearing on the hind legs at the corner or along the side walls of the cage, and jumping in such a way as both hind legs are simultaneously off the ground.

\section{Statistical analysis}

All of the analyses were made using GraphPad Prism 8.0.2 software and one-way analysis of variance (ANOVA) followed by Bonferroni's or Tukey's post hoc test. An unpaired t-test was used for twosample comparisons. Two sample comparison were made with unpaired t-test if data was normally distributed, and with a parametric test if data was not normally distributed. Three groups were analysed with one-way ANOVA followed by Tukey post-hoc test. All of data are expressed as mean values \pm the standard error of the mean (SEM).

\section{$\underline{\text { References }}$}

1. SACHS BD (1988): The Development of Grooming and Its Expression in Adult Animals. Ann N Y Acad Sci 525: 1-17. 
bioRxiv preprint doi: https://doi.org/10.1101/2021.01.27.428434; this version posted January 27, 2021. The copyright holder for this preprint (which was not certified by peer review) is the author/funder. All rights reserved. No reuse allowed without permission.

Astrocytic origin of pathological grooming

Petrelli, Zehnder et al. 2020

2. Berridge KC, Aldridge JW (2000): Super-stereotypy II: Enhancement of a complex movement sequence by systemic dopamine D1 agonists. Synapse 37: 194-204.

3. Berridge KC, Fentress JC, Parr H (1987): Natural syntax rules control action sequence of rats. Behav Brain Res 23: 59-68.

4. Kalueff A V., Stewart AM, Song C, Berridge KC, Graybiel AM, Fentress JC (2016): Neurobiology of rodent self-grooming and its value for translational neuroscience. Nat Rev Neurosci 17: 45-59.

5. Graybiel AM, Rauch SL (2000): Toward a Neurobiology Review of Obsessive-Compulsive Disorder. Neuron 28: 343-347.

6. Pauls David L. (2010): The genetics of obsessive-compulsive disorder: a review. Dialogues Clin Neurosci 12: 149-163.

7. Meier SM, Mattheisen M, Mors O, Schendel DE, Mortensen PB, Plessen KJ (2016): Mortality among persons with obsessive-compulsive disorder in Denmark. JAMA Psychiatry 73: 268-274.

8. Murray CJ., Lopez AD (1996): Global Burden of Disease and Injur Y Series the Global Burden of Disease. Oms 1-46.

9. Pérez-Vigil A, De La Cruz LF, Brander G, Isomura K, Jangmo A, Feldman I, et al. (2018): Association of obsessive-compulsive disorder with objective indicators of educational attainment: A nationwide register-based sibling control study. JAMA Psychiatry 75: 47-55.

10. Lochner C, Fineberg NA, Zohar J, Van Ameringen M, Juven-Wetzler A, Altamura AC, et al. (2014): Comorbidity in obsessive-compulsive disorder (OCD): A report from the International College of Obsessive-Compulsive Spectrum Disorders (ICOCS). Compr Psychiatry 55: 1513-1519.

11. Swedo SE, Snider LA (n.d.): in. Neurobiology of Mental Illness (Eds Nestler, E. J. \& Charney, D. S.). pp 628-638.

12. Ahmari SE, Dougherty DD (2015): DISSECTING OCD CIRCUITS: From ANIMAL MODELS to TARGETED TREATMENTS. Depress Anxiety 32: 550-562.

13. Ting JT, Feng G (2011): Neurobiology of obsessive-compulsive disorder: Insights into neural circuitry dysfunction through mouse genetics. Curr Opin Neurobiol 21: 842-848.

14. Welch JM, Lu J, Rodriguiz RM, Trotta NC, Peca J, Ding JD, et al. (2007): Cortico-striatal synaptic defects and OCD-like behaviours in Sapap3-mutant mice. Nature 448: 894-900.

15. Chen M, Wan Y, Ade K, Ting J, Feng G, Calakos N (2011): Sapap3 deletion anomalously activates short-term endocannabinoid-mediated synaptic plasticity. J Neurosci 31: 9563-9573.

16. Shmelkov S V., Hormigo A, Jing D, Proenca CC, Bath KG, Milde T, et al. (2010): Slitrk5 deficiency impairs corticostriatal circuitry and leads to obsessive-compulsive-like behaviors in mice. Nat Med 16: $598-602$.

17. Burguière E, Monteiro P, Feng G, Graybiel AM (2013): Optogenetic Stimulation of Lateral. Science (80- ) 340: 1243-1246.

18. Baxter LR, Thompson JM, Schwartz JM, Guze BH, Phelps ME, Mazziotta JC, et al. (1987): Trazodone Treatment Response in Obsessive-Compulsive Disorder -Correlated with shifts in 
bioRxiv preprint doi: https://doi.org/10.1101/2021.01.27.428434; this version posted January 27, 2021. The copyright holder for this preprint (which was not certified by peer review) is the author/funder. All rights reserved. No reuse allowed without permission.

Glucose Metabolism in the Caudate Nuclei. Psychopathology 20: 114-122.

19. Breiter HC, Rauch SL, Kwong KK, Baker JR, Weisskoff RM, Kennedy DN, et al. (1996): Functional Magnetic Resonance Imaging of Symptom Provocation in Obsessive-compulsive Disorder. Arch Gen Psychiatry 53: 595-606.

20. Rauch SL, Fischman AJ (1994): Regional Cerebral Blood Flow Measured During Symptom Provocation in Obsessive-Compulsive Disorder Using Oxygen 15-Labeled Carbon Dioxide and Positron Emission Tomography. Arch Gen Psychiatry 51: 62-70.

21. Manning EE, Ahmari SE (2018): How can preclinical mouse models be used to gain insight into prefrontal cortex dysfunction in obsessive-compulsive disorder? Brain Neurosci Adv 2: 239821281878389.

22. Gruner P, Pittenger C (2017): Cognitive inflexibility in Obsessive-Compulsive Disorder. Neuroscience 345: 243-255.

23. Benzina N, Mallet L, Burguière E, N'Diaye K, Pelissolo A (2016): Cognitive Dysfunction in Obsessive-Compulsive Disorder. Curr Psychiatry Rep 18. https://doi.org/10.1007/s11920-0160720-3

24. van den Boom BJG, Mooij AH, Misevičiūtė I, Denys D, Willuhn I (2019): Behavioral flexibility in a mouse model for obsessive-compulsive disorder: Impaired Pavlovian reversal learning in SAPAP3 mutants. Genes, Brain Behav 18: 1-11.

25. Manning EE, Dombrovski AY, Torregrossa MM, Ahmari SE (2019): Impaired instrumental reversal learning is associated with increased medial prefrontal cortex activity in Sapap3 knockout mouse model of compulsive behavior. Neuropsychopharmacology 44: 1494-1504.

26. Hadjas LC, Lüscher C, Simmler LD (2019): Aberrant habit formation in the Sapap3-knockout mouse model of obsessive-compulsive disorder. Sci Rep 9: 1-9.

27. Greer JM, Capecchi MR (2002): Hoxb8 Is Required for Normal Grooming Behavior in Mice. Neuron 33: 23-34.

28. Chen SK, Tvrdik P, Peden E, Cho S, Wu S, Spangrude G, Capecchi MR (2010): Hematopoietic origin of pathological grooming in Hoxb8 mutant mice. Cell 141: 775-785.

29. Ozomaro U, Cai G, Kajiwara Y, Yoon S, Makarov V, Delorme R, et al. (2013): Characterization of SLITRK1 Variation in Obsessive-Compulsive Disorder. PLoS One 8: 1-7.

30. Wendland JR, Kruse MR, Murphy DL (2006): Functional SLITRK1 var321, varCDfs and SLC6A4 G56A variants and susceptibility to obsessive-compulsive disorder [4]. Mol Psychiatry 11: 802804.

31. Ahmari SE, Spellman T, Douglass NL, Kheirbek MA, Simpson HB, Deisseroth K, et al. (2013): Repeated cortico-striatal stimulation generates persistent OCD-like behavior. Science (80- ) 340: $1234-1239$.

32. Hemmings SMJ, Kinnear CJ, Niehaus DJH, Moolman-Smook JC, Lochner C, Knowles JA, et al. (2003): Investigating the role of dopaminergic and serotonergic candidate genes in obsessive- 
bioRxiv preprint doi: https://doi.org/10.1101/2021.01.27.428434; this version posted January 27, 2021. The copyright holder for this preprint (which was not certified by peer review) is the author/funder. All rights reserved. No reuse allowed without permission.

compulsive disorder. Eur Neuropsychopharmacol 13: 93-98.

33. Muscatello MRA, Bruno A, Pandolfo G, Micò U, Scimeca G, Romeo VM, et al. (2011): Effect of aripiprazole augmentation of serotonin reuptake inhibitors or clomipramine in treatment-resistant obsessive-compulsive disorder: A double-blind, placebo-controlled study. $J$ Clin Psychopharmacol 31: 174-179.

34. Stein BDJ, Ipser JC, Baldwin DS (2007): Treatment of Obsessive-Compulsive Disorder. CNS Spectr 12:1: $28-35$.

35. Storch EA, Bussing R, Small BJ, Geffken GR, McNamara JP, Rahman O, et al. (2013): Randomized, placebo-controlled trial of cognitive-behavioral therapy alone or combined with sertraline in the treatment of pediatric obsessive-compulsive disorder. Behav Res Ther 51: 823-829.

36. Swedo SE, Leonard HL, Rapoport JL, Lenane MC (1989): A Double-Blind Comparison of Clomipramine and Desipramine in the Treatment of Trichotillomania (Hair Pulling). N Engl J Med 321: 497-501.

37. Swedo SE, Lenane MC, Leonard HL (1993): Long-Term Treatment of Trichotillomania (Hair Pulling). N Engl J Med 329: 141-142.

38. McGuire JF, Lewin AB, Storch EA (2014): Enhancing exposure therapy for anxiety disorders, obsessive-compulsive disorder and post-traumatic stress disorder. Expert Rev Neurother 14: 893910.

39. Jenike MA (2004): Clinical Practice. Obsessive-compulsive disorder. $N$ Engl J Med 350: 259-65.

40. Eagle DM, Noschang C, d'Angelo LSC, Noble CA, Day JO, Dongelmans ML, et al. (2014): The dopamine D2/D3 receptor agonist quinpirole increases checking-like behaviour in an operant observing response task with uncertain reinforcement: A novel possible model of OCD. Behav Brain Res 264: 207-229.

41. Karayiorgou M, Sobin C, Blundell ML, Galke BL, Malinova L, Goldberg P, et al. (1999): Familybased association studies support a sexually dimorphic effect of COMT and MAOA on genetic susceptibility to obsessive-compulsive disorder. Biol Psychiatry 45: 1178-1189.

42. Van Ameringen M, Mancini C, Oakman JM, Farvolden P (1999): The potential role of haloperidol in the treatment of trichotillomania. J Affect Disord 56: 219-226.

43. Van Ameringen M, Simpson W, Patterson B, Dell'Osso B, Fineberg N, Hollander E, et al. (2014): Pharmacological treatment strategies in obsessive compulsive disorder: A cross-sectional view in nine international OCD centers. J Psychopharmacol 28: 596-602.

44. Koo MS, Kim EJ, Roh D, Kim CH (2010): Role of dopamine in the pathophysiology and treatment of obsessive - Compulsive disorder. Expert Rev Neurother 10: 275-290.

45. Abudy A (2011): Pharmacological management of Treatment-Resistant Obsessive-Compulsive Disorder. CNS Drugs 27: 118-121.

46. Greist JH, Jefferson JW, Kobak KA, Katzelnick DJ, Serlin RC (1995): Efficacy and Tolerability of Serotonin Transport Inhibitors in Obsessive-compulsive Disorder: A Meta-analysis. Arch Gen 
Psychiatry 52: 53-60.

47. Mcdougle CJ, Goodman WK, Leckman JF, Price LH (1994): Haloperidol Addition in FluvoxamineRefractory Obsessive Compulsive Disorder. Arch Gen Psychiatry 51: 302-308.

48. Denys D, Zohar J, Westenberg HGM (2004): The role of dopamine in obsessive-compulsive disorder: Preclinical and clinical evidence. J Clin Psychiatry 65: 11-17.

49. Zhang W, Perry KW, Wong DT, Potts BD, Bao J, Tollefson GD, Bymaster FP (2000): Synergistic Effects of Olanzapine and Other Antipsychotic Agents in Combination with Fluoxetine on Norepinephrine and Dopamine Release in Rat Prefrontal Cortex. Neuropsychopharmacology 23: $250-262$.

50. Petrelli F, Dallérac G, Pucci L, Calì C, Zehnder T, Sultan S, et al. (2020): Dysfunction of homeostatic control of dopamine by astrocytes in the developing prefrontal cortex leads to cognitive impairments. Mol Psychiatry 25: 732-749.

51. Edwards RH (2007): The Neurotransmitter Cycle and Quantal Size. Neuron 55: 835-858.

52. Lioy DT, Garg SK, Monaghan CE, Raber J, Foust KD, Kaspar BK, et al. (2011): A role for glia in the progression of Rett-syndrome. Nature 475: 497-500.

53. Narboux-Nême N, Sagné C, Doly S, Diaz SL, Martin CBP, Angenard G, et al. (2011): Severe Serotonin Depletion after Conditional Deletion of the Vesicular Monoamine Transporter 2 Gene in Serotonin Neurons: Neural and Behavioral Consequences. Neuropsychopharmacology 36: $2538-2550$.

54. Zehnder T, Petrelli F, Romanos J, De Oliveira Figueiredo EC, Lewis T, Déglon N, et al. (2021): Mitochondria in developing astrocytes regulate astrocytes maturation and promote synapse formation.Submitted.

55. Won H, Lee HR, Gee HY, Mah W, Kim JI, Lee J, et al. (2012): Autistic-like social behaviour in Shank2-mutant mice improved by restoring NMDA receptor function. Nature 486: 261-265.

56. Züchner S, Wendland JR, Ashley-Koch AE (2009): Multiple rare SAPAP3 missense variants in trichotillomania and OCD. Mol Psychiatry 14: 6-9.

57. Monteiro P, Feng G (2016): Learning from animal models of obsessive-compulsive disorder. Biol Psychiatry 79: 7-16.

58. Hadjas LC, Schartner MM, Cand J, Creed MC, Pascoli V, Lüscher C, Simmler LD (2020): Projection-specific deficits in synaptic transmission in adult Sapap3-knockout mice. Neuropsychopharmacology 45: 2020-2029.

59. Piantadosi SC, Ahmari SE (2015): Using Optogenetics to Dissect the Neural Circuits Underlying OCD and Related Disorders. Curr Treat Options Psychiatry 2: 297-311.

60. Klapoetke NC, Murata Y, Kim SS, Pulver SR (2014): Independent Optical Excitation of Distinct Neural Populations. Nat Methods 11: 338-346.

61. Pascoli V, Turiault M, Lüscher C (2012): Reversal of cocaine-evoked synaptic potentiation resets drug-induced adaptive behaviour. Nature 481: 71-76. 
62. Colin A, Faideau M, Dufour N, Auregan G, Hassig R, Andrieu T, et al. (2009): Engineered lentiviral vector targeting astrocytes in vivo. Glia 57: 667-679.

63. Cui M, Aras R, Christian W V., Rappold PM, Hatwar M, Panza J, et al. (2009): The organic cation transporter-3 is a pivotal modulator of neurodegeneration in the nigrostriatal dopaminergic pathway. Proc Natl Acad Sci U S A 106: 8043-8048.

64. Yoshikawa T, Naganuma F, lida T, Nakamura T, Harada R, Mohsen AS, et al. (2013): Molecular Mechanism of Histamine Clearance by Primary Human Astrocytes. Glia 61: 905-916.

65. Oberheim NA, Takano T, Han X, He W, Lin JHC, Wang F, et al. (2009): Uniquely hominid features of adult human astrocytes. J Neurosci 29: 3276-3287.

66. Frances AJ, Pincus HA, First B, Ross R, Davis W (2013): American Psychiatric Association (2013). Diagnostic and Statistical Manual of Mental Disorders., 5th ed.

67. Lamothe H, Baleyte JM, Mallet L, Pelissolo A (2020): Trichotillomania is more related to tourette disorder than to obsessive-compulsive disorder. Brazilian J Psychiatry 42: 87-104.

68. Denys D (2014): Compulsivity and free will. CNS Spectr 19: 8-9.

69. Ruscio AM, Stein DJ, Chiu WT, Kessler RC (2010): The Epidemiology of Obsessive-Compulsive Disorder in the National Comorbidity Survey Replication. Mol Psychiatry 15: 53-63.

70. Berridge KC, Whishaw IQ (1992): Cortex, striatum and cerebellum: control of serial order in a grooming sequence. Exp Brain Res 90: 275-290.

71. Hunnicutt BJ, Jongbloets BC, Birdsong WT, Gertz KJ, Zhong H, Mao T (2016): A comprehensive excitatory input map of the striatum reveals novel functional organization. Elife 5: 1-32.

72. Graybiel AM, Aosaki T, Flaherty AW, Kimura M (1994): The Basal Ganglia and Adaptive Motor Control. Science (80- ) 265: 1826-1831.

73. Gillan CM, Robbins TW (2014): Goal-directed learning and obsessive - compulsive disorder. Philos Trans $R$ Soc B 369: 1-11.

74. McCracken CB, Grace AA (2013): Persistent cocaine-induced reversal learning deficits are associated with altered limbic cortico-striatal local field potential synchronization. J Neurosci 33: 17469-17482.

75. Chen BT, Yau HJ, Hatch C, Kusumoto-Yoshida I, Cho SL, Hopf FW, Bonci A (2013): Rescuing cocaine-induced prefrontal cortex hypoactivity prevents compulsive cocaine seeking. Nature 496: $359-362$.

76. Liu Y, Edwards RH (1997): The role of vesicular transport proteins in synaptic transmission and neural degeneration. Annu Rev Neurosci 20: 125-156.

77. Fon EA, Pothos EN, Sun BC, Killeen N, Sulzer D, Edwards RH (1997): Vesicular transport regulates monoamine storage and release but is not essential for amphetamine action. Neuron 19: 12711283.

78. Wang YM, Gainetdinov RR, Fumagalli F, Xu F, Jones SR, Bock CB, et al. (1997): Knockout of the vesicular monoamine transporter 2 gene results in neonatal death and supersensitivity to cocaine 
bioRxiv preprint doi: https://doi.org/10.1101/2021.01.27.428434; this version posted January 27, 2021. The copyright holder for this preprint (which was not certified by peer review) is the author/funder. All rights reserved. No reuse allowed without permission.

and amphetamine. Neuron 19: 1285-1296.

79. Chu TT, Liu Y (2010): An integrated genomic analysis of gene-function correlation on schizophrenia susceptibility genes. J Hum Genet 55: 285-292.

80. Lin Z, Walther D, Yu XY, Li S, Drgon T, Uhl GR (2005): SLC18A2 promoter haplotypes and identification of a novel protective factor against alcoholism. Hum Mol Genet 14: 1393-1404.

81. Jacobsen JC, Wilson C, Cunningham V, Glamuzina E, Prosser DO, Love DR, et al. (2016): Brain dopamine-serotonin vesicular transport disease presenting as a severe infantile hypotonic parkinsonian disorder. J Inherit Metab Dis 39: 305-308.

82. Rath M, Korenke GC, Najm J, Hoffmann GF, Hagendorff A, Strom TM, Felbor U (2017): Exome sequencing results in identification and treatment of brain dopamine-serotonin vesicular transport disease. J Neurol Sci 379: 296-297.

83. Rilstone JJ, Alkhater RA, Minassian BA (2013): Brain Dopamine-Serotonin Vesicular Transport Disease and Its Treatment. N Engl J Med 368: 543-550.

84. Romero-Calderón R, Uhlenbrock G, Borycz J, Simon AF, Grygoruk A, Yee SK, et al. (2008): A Glial Variant of the Vesicular Monoamine Transporter is Required to Store Histamine in the Drosophila Visual System. PLoS Genet 4. https://doi.org/10.1371/journal.pgen.1000245

85. Hirrlinger PG, Scheller A, Braun C, Hirrlinger J, Kirchhoff F (2006): Temporal Control of Gene Recombination in Astrocytes by Transgenic Expression of the Tamoxifen-Inducible DNA Recombinase Variant CreERT2. Glia 54: 11-20.

86. Srinivas S, Watanabe T, Lin CS, William CM, Tanabe Y, Jessell TM, Costantini F (2001): Cre reporter strains produced by targeted insertion of EYFP and ECFP into the ROSA26 locus. BMC Dev Biol 1: 1-8.

87. Escartin C, Brouillet E, Gubellini P, Trioulier Y, Jacquard C, Smadja C, et al. (2006): Ciliary neurotrophic factor activates astrocytes, redistributes their glutamate transporters GLAST and GLT-1 to raft microdomains, and improves glutamate handling in vivo. J Neurosci 26: 5978-5989.

88. Schubert V, Bouvier D, Volterra A (2011): SNARE protein expression in synaptic terminals and astrocytes in the adult hippocampus: A comparative analysis. Glia 59: 1472-1488.

89. Knott GW, Holtmaat A, Wilbrecht L, Welker E, Svoboda K (2006): Spine growth precedes synapse formation in the adult neocortex in vivo. Nat Neurosci 9: 1117-1124.

90. Cahoy JD, Emery B, Kaushal A, Foo LC, Zamanian JL, Christopherson KS, et al. (2008): A transcriptome database for astrocytes, neurons, and oligodendrocytes: A new resource for understanding brain development and function. J Neurosci 28: 264-278.

91. Prada I, Marchaland J, Podini P, Magrassi L., D'Alessandro R, Bezzi P, Meldolesi J (2011) REST/NRSF governs the expression of dense-core vesicle gliosecretion in astrocytes. $J$ Cell Biol 193:537-49

92. Sultan S, Li L, Moss J, Petrelli F, Cassé F, Gebara E, et al. (2015): Synaptic Integration of AdultBorn Hippocampal Neurons Is Locally Controlled by Astrocytes. Neuron 88: 957-972. 
bioRxiv preprint doi: https://doi.org/10.1101/2021.01.27.428434; this version posted January 27, 2021. The copyright holder for this preprint (which was not certified by peer review) is the author/funder. All rights reserved. No reuse allowed without permission.

Astrocytic origin of pathological grooming

Petrelli, Zehnder et al. 2020 
본

로
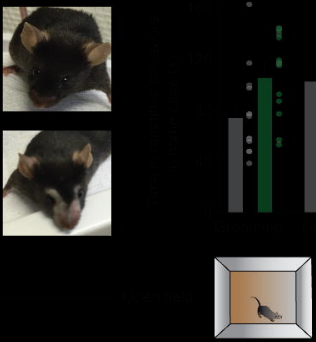

2)

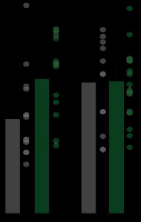

8ิ
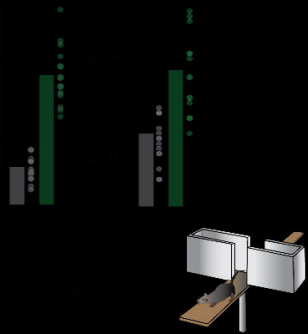
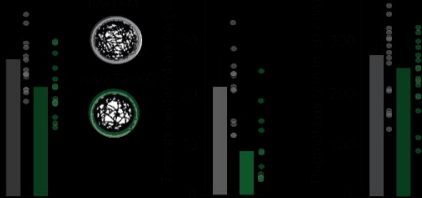

e

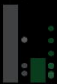




\section{AAV8-Syn-ChrimsonR-GFP}
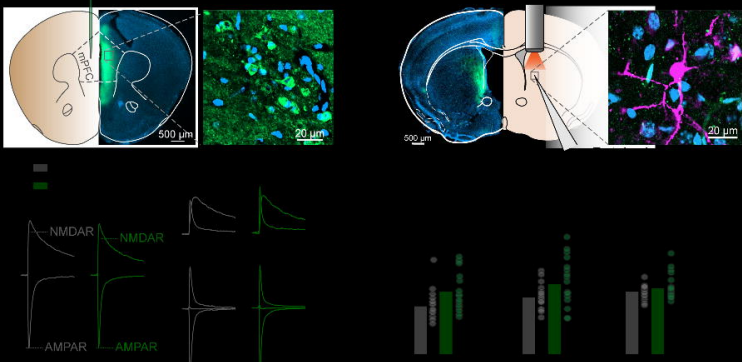


\section{Figure 3}

Astrocyte-specific Lenti-GFP/VMAT2
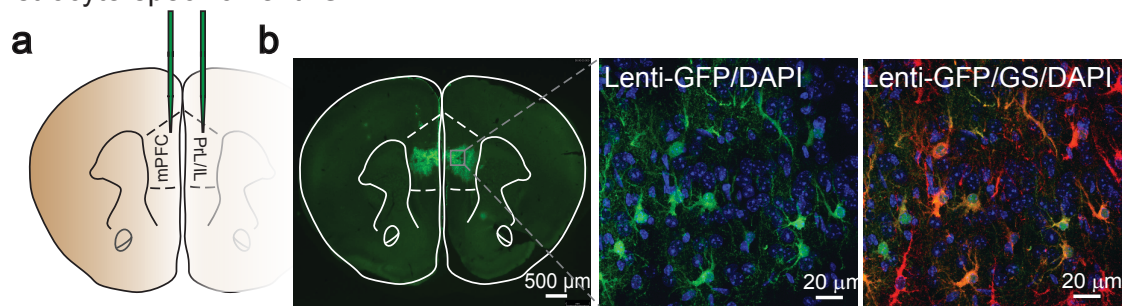

IentivMAT2 injection

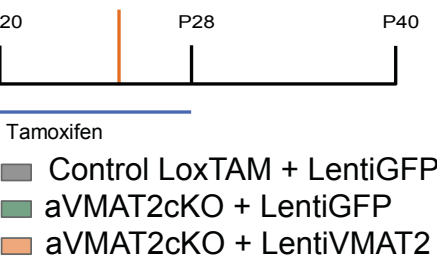

Repetitive behavior

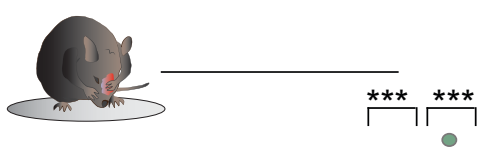

C

(0)

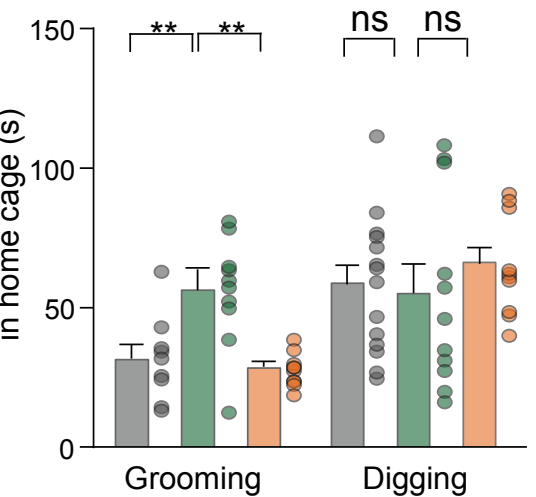

Open field

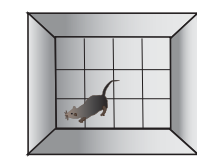

g

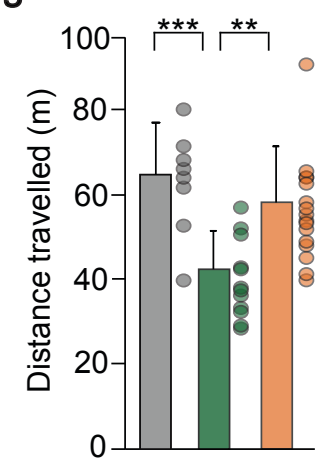

d

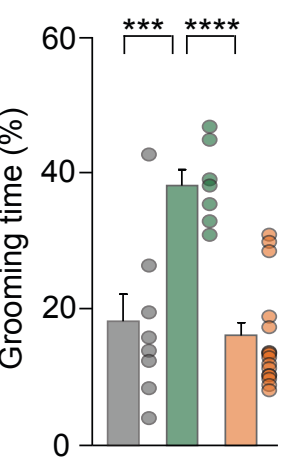

e

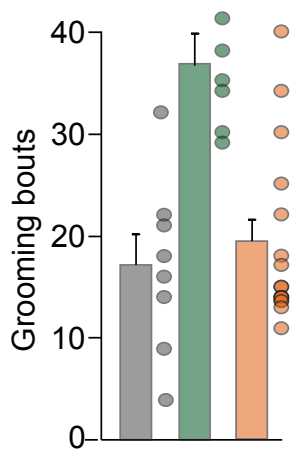

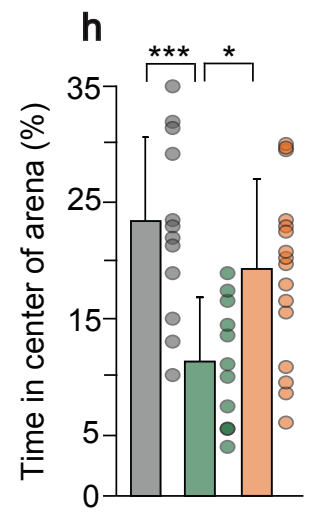

Elevated plus maze

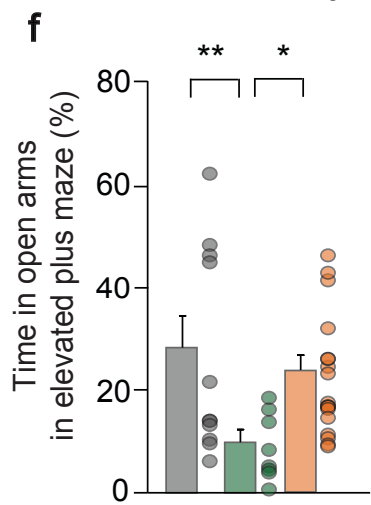

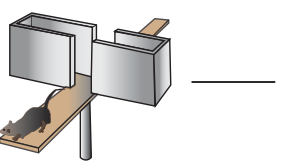
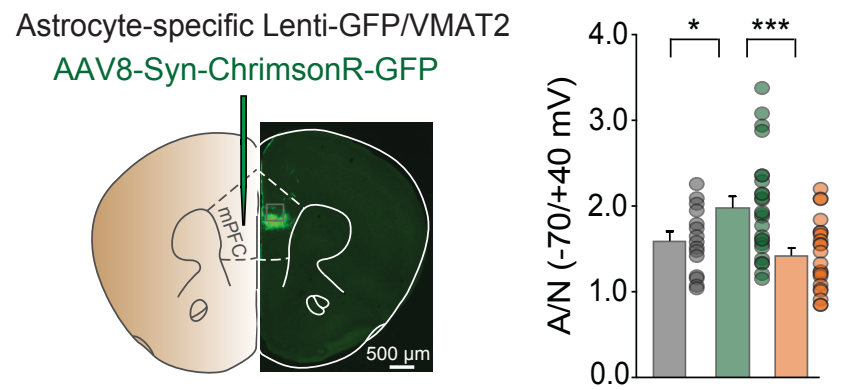
Figure 4

a

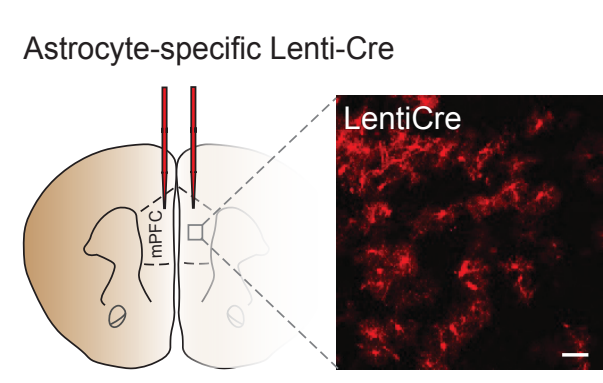

C

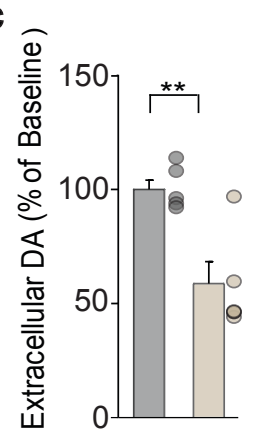

d

$$
\square \text { Lenti GFP }
$$
$\square$ Lenti Cre
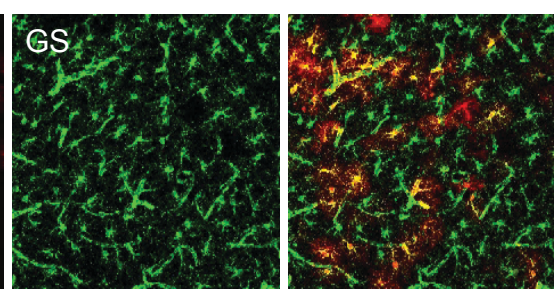

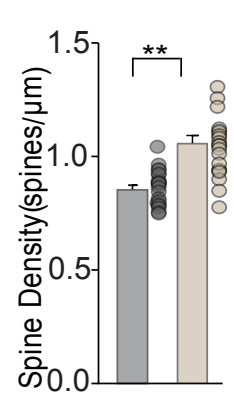

e Lenti GFPLenti Cre

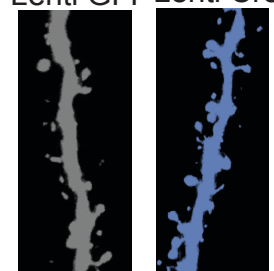

Repetitive behavior
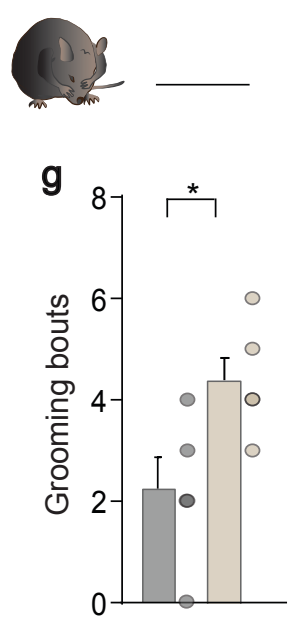
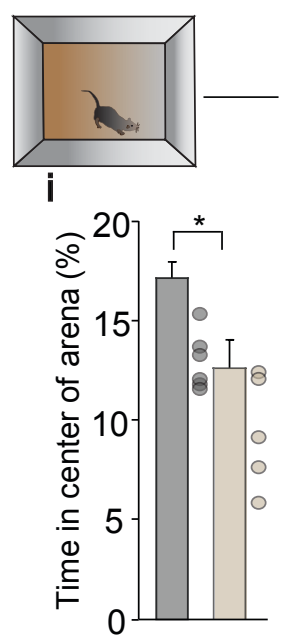

Elevated plus maze

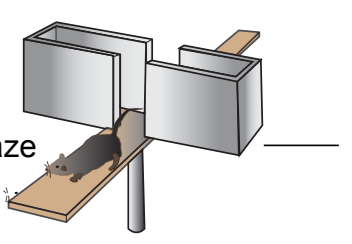

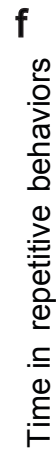

80] *

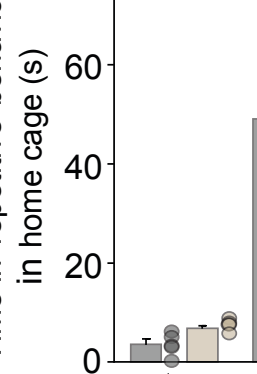

○ 0

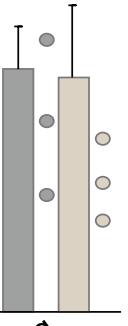

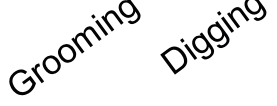
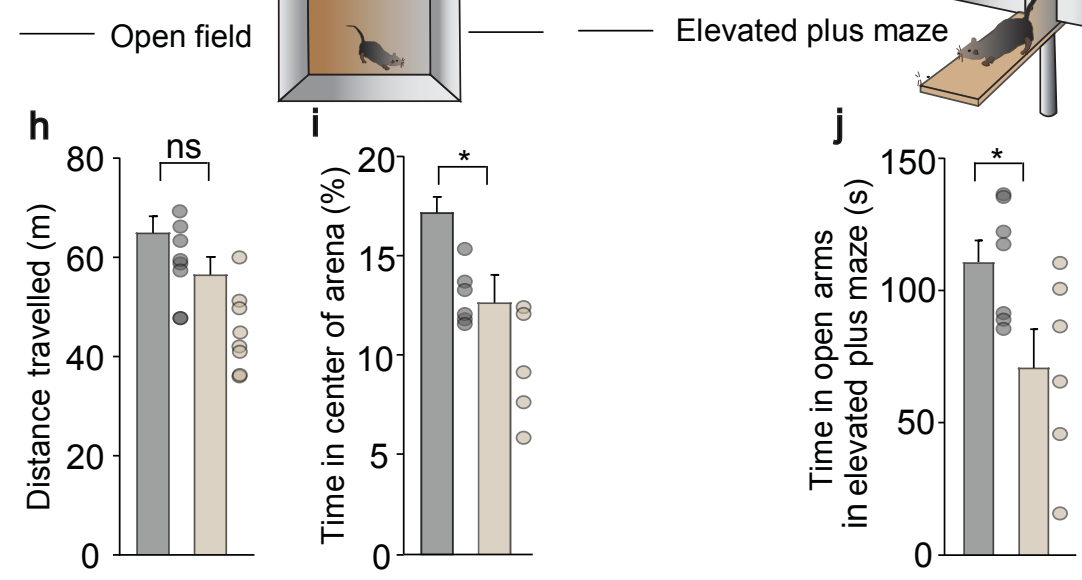
Figure 5

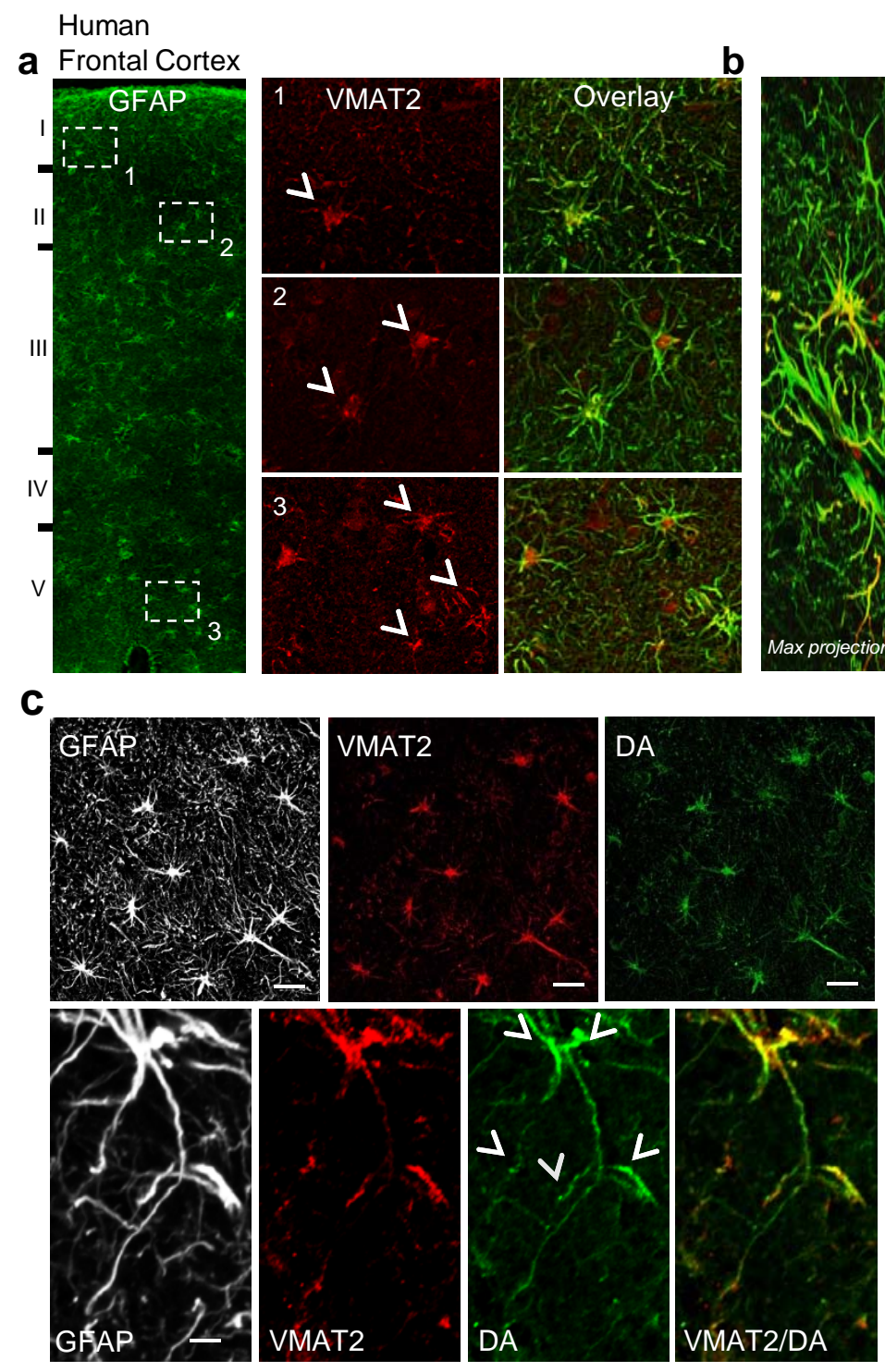

